\title{
Understanding the Processes Causing the Early Intensification of Hurricane Dorian through an Ensemble of the Hurricane Analysis and Forecast System (HAFS)
}

\author{
Andrew Hazelton ${ }^{1,2, *} \mathbb{0}$, Ghassan J. Alaka, Jr. ${ }^{2} \mathbb{D}$, Levi Cowan ${ }^{1,2}$, Michael Fischer ${ }^{2}$ \\ and Sundararaman Gopalakrishnan ${ }^{2}$ \\ 1 Cooperative Institute for Marine and Atmospheric Studies, University of Miami, Miami, FL 33149, USA; \\ Levi.Cowan@noaa.gov \\ 2 National Oceanic and Atmospheric Administration Atlantic Oceanographic and Meteorological Laboratories, \\ Hurricane Research Division, Miami, FL 33149, USA; Ghassan.Alaka@noaa.gov (G.J.A.J.); \\ Michael.Fischer@noaa.gov (M.F.); sundararaman.g.gopalakrishnan@noaa.gov (S.G.) \\ * Correspondence: Andrew.Hazelton@noaa.gov
}

Citation: Hazelton, A.; Alaka, G.J. Jr.; Cowan, L.; Fischer, M.; Gopalakrishnan, S. Understanding the Processes Causing the Early Intensification of Hurricane Dorian through an Ensemble of the Hurricane Analysis and Forecast System (HAFS). Atmosphere 2021, 12, 93. https://doi.org/10.3390/ atmos12010093

Received: 1 December 2020 Accepted: 7 January 2021 Published: 10 January 2021

Publisher's Note: MDPI stays neutral with regard to jurisdictional clai$\mathrm{ms}$ in published maps and institutional affiliations.

Copyright: (C) 2021 by the authors. Licensee MDPI, Basel, Switzerland. This article is an open access article distributed under the terms and conditions of the Creative Commons Attribution (CC BY) license (https:// creativecommons.org/licenses/by/ $4.0 /)$.

\begin{abstract}
The early stages of a tropical cyclone can be a challenge to forecast, as a storm consolidates and begins to grow based on the local and environmental conditions. A high-resolution ensemble of the Hurricane Analysis and Forecast System (HAFS) is used to study the early intensification of Hurricane Dorian, a catastrophic 2019 storm in which the early period proved challenging for forecasters. There was a clear connection in the ensemble between early storm track and intensity: stronger members moved more northeast initially, although this result did not have much impact on the long-term track. The ensemble results show several key factors determining the early evolution of Dorian. Large-scale divergence northeast of the tropical cyclone (TC) appeared to favor intensification, and this structure was present at model initialization. There was also greater moisture northeast of the TC for stronger members at initialization, favoring more intensification and downshear development of the circulation as these members evolved. This study highlights the complex interplay between synoptic and storm scale processes in the development and intensification of early-stage tropical cyclones.
\end{abstract}

Keywords: hurricane; tropical cyclone; ensemble; intensification

\section{Introduction}

Understanding the processes underlying tropical cyclone intensity change continues to be a major goal of research in tropical meteorology. Predicting tropical cyclone (TC) intensity change is important for many reasons, including providing accurate warnings of potential impacts. TC intensity can also affect the track a TC will take [1], and the interplay between them can prove to be very difficult in some forecast scenarios. In this study, we examine the complexities associated with the early intensification of Hurricane Dorian (2019), one of the most devastating and powerful tropical cyclones of the 21st century [2]. The study explores key factors that allowed Dorian to intensify in the Eastern Caribbean despite the presence of marginal to hostile environmental conditions (including dry air), and the connection between the track and intensity of the TC during this critical early period.

The link between TC structure and forecast errors of track and intensity, and sources of forecast uncertainty, are both topics of interest in the tropical meteorology community. Davis and Bosart [3] studied numerical simulations of Hurricane Diana (1984), and found that its track was sensitive to the cumulus scheme chosen, because of how the associated precipitation and outflow affected the large-scale steering of the storm. Bassill [4] found a similar sensitivity of the modeled track of Hurricane Sandy (2012) to cumulus parameterization. Torn and Snyder [5] found that initial position uncertainty tends to be higher for weaker storms (when the vortex may be broad and ill-defined). Alaka et al. [6] 
used an ensemble of Hurricane Weather Research and Forecasting (HWRF) model runs to study the evolution of Hurricane Joaquin (2015). They found that the track of the TC did not seem to be sensitive to the initial vortex location or intensity, but rather was much more sensitive to subtle differences in the synoptic environment. Nystrom et al. [7] also examined Hurricane Joaquin, using an ensemble of WRF runs. They found that the track of the TC was most sensitive to differences in the initial conditions $600-900 \mathrm{~km}$ from the TC center, while intensity was most sensitive to initial conditions in the $300 \mathrm{~km}$ closest to the TC. What is clear from these studies is that TC track and intensity can be sensitive to a number of environmental and local perturbations, and the relative contributions of local and large-scale factors can be different for different cases. Here, we explore which factors were most important for allowing Dorian to intensify and move further northeast than initially forecasted in the Eastern Caribbean.

Ensemble systems are a useful tool for studying the uncertainty of certain TC forecasts and setups. Zhang and Krishnamurti [8] was an early study that used an ensemble setup to study TC track forecasts and the sensitivity to perturbations in both TC location and the environment around the TC. More recent studies have utilized an ensemble approach to elucidate details of TC intensification and evolution, especially in sheared or otherwise hostile environments. Leighton et al. [9] used an ensemble of HWRF forecasts to examine the intensification of Hurricane Edouard (2014) and found that both vortex-scale processes (like vortex tilt and eddy radial vorticity flux) as well as environmental factors (such as environmental moisture) were key in distinguishing between intensifying and non-intensifying members. Rios-Berrios et al. [10] similarly demonstrated the importance of moisture to the intensification of Hurricane Katia (2011) using the ensemble of Advanced Hurricane WRF (AHW). As these and other studies demonstrate, ensembles are a useful tool for evaluating complex and uncertain processes in TC formation and evolution. Such complex processes were at work in the early evolution of Dorian.

Here, we make use of an ensemble set based on the Hurricane Analysis and Forecast System (HAFS), which uses the nested version of the finite-volume cubed sphere (FV3) dynamical core. Similar versions of high-resolution nested FV3 have been used both for realtime prediction [11] and comparison with observational datasets [12], and demonstrated the capability of this model for high-resolution TC prediction. HAFS is a developing component of the Unified Forecast System (UFS) [13].

\section{Experiments}

\subsection{Hurricane Dorian Background}

Hurricane Dorian was the strongest hurricane of the 2019 Atlantic Hurricane season, and also the strongest hurricane to impact the Bahamas in recorded history [2]. Dorian was a small storm that formed in the Central Atlantic, and then moved into the Eastern Caribbean Sea and then the Southwest Atlantic. It rapidly intensified and became a Category 5 Hurricane before impacting the northern Bahamas with devastating wind, rain, and storm surge. Dorian slowed to a crawl, stalled, and then recurved and impacted the Outer Banks of North Carolina as a Category 1 hurricane. One of the biggest forecast challenges with Dorian was the motion and intensity change early in its lifecycle, while the storm was moving through and past the Lesser Antilles. This period included a "jump" of the center north of the previous position [2]. During this time, Hurricane Dorian also intensified more than most forecasts suggested [2], and became a hurricane while moving northwest through the Virgin Islands. This early period of intensification, the factors that led to this unexpected intensification, and the connection to the track of the TC will be explored in this study. 


\subsection{Model Setup}

This study uses the global-nested Hurricane Analysis and Forecast System [14]. This model (referred to as HAFS-globalnest hereafter) is based on a nested version of FV3GFS [15] that features two-way feedback between the nested grid and the global domain. The nested grid layout is the same as that used in a large set of real-time forecast experiments from the 2019 Atlantic Hurricane Season. See Figure 1 for details of the nest layout.

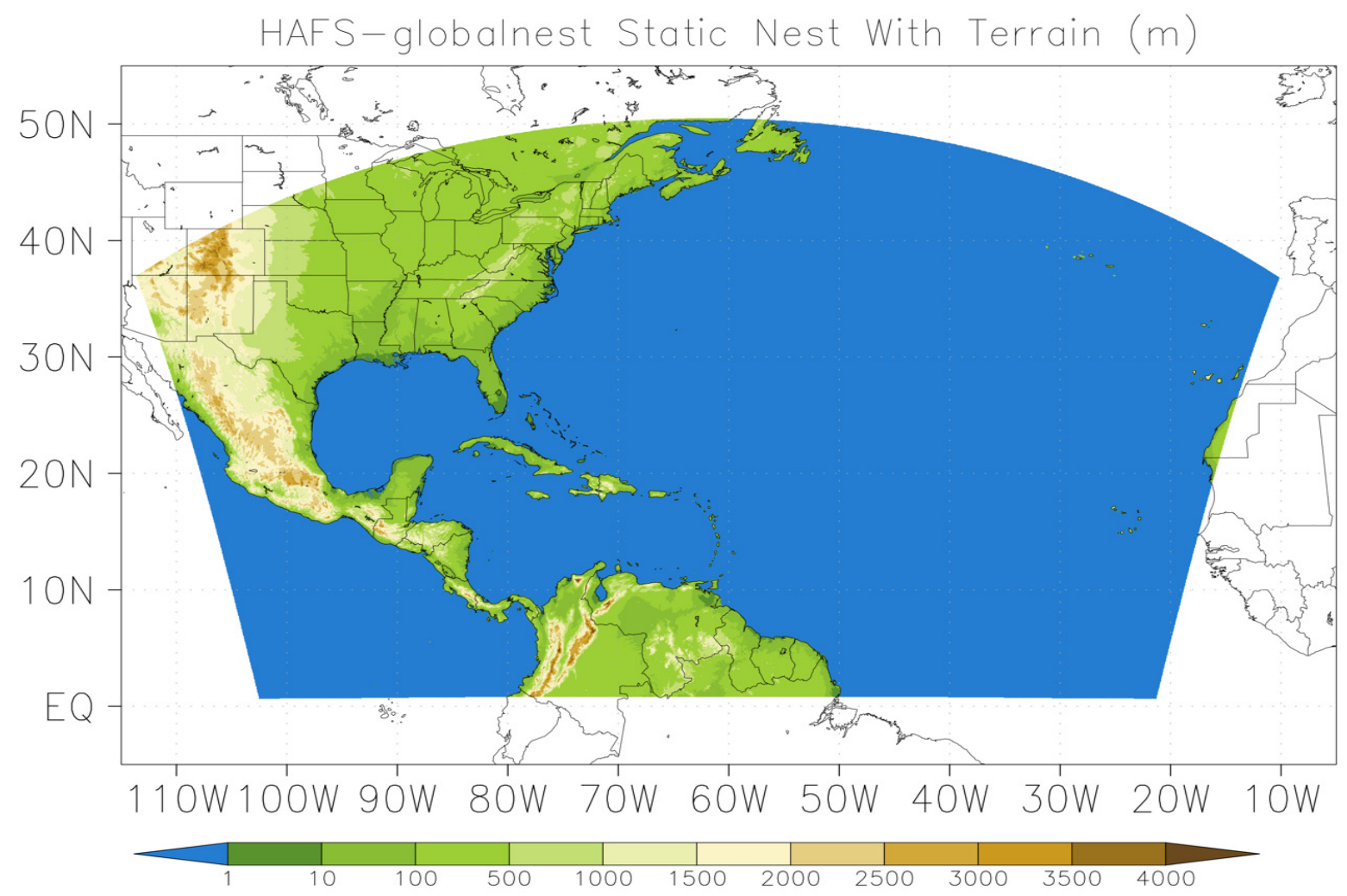

Figure 1. Hurricane Analysis and Forecast System (HAFS)-globalnest static nest domain (illustrated by terrain height, shaded) covering the North Atlantic.

HAFS-globalnest uses physics parameterizations that are similar to the operational GFS model, with some key modifications to account for changes in the tropical cyclone environment. The convective parameterization [16] is used on the global domain, but not on the 3-km nest. The GFS EDMF planetary boundary layer (PBL) scheme [17] is used, with modifications to be more consistent with observed eddy diffusivity and PBL structure in the TC environment $[18,19]$. For radiation, HAFS-globalnest uses the rapid radiation transfer model for GCMs (RRTMG) [20]. The microphysics scheme is the 6-class single moment GFDL microphysics [21]. The surface scheme accounts for changes in drag coefficient at high wind speeds in the TC core [22].

For the analysis in this study, an 80-member ensemble is used, created by initializing the model from 80 different members from the Global Ensemble Forecast System (GEFS), which uses an 80-member Ensemble Kalman Filter (EnKF) data assimilation system [23]. A similar methodology was applied to initialize a 40-member HFV3 (a nested FV3GFS predecessor to HAFS) forecast ensemble to study the rapid intensification of Hurricane Michael (2018) [14]. The ensemble forecasts for Hurricane Dorian were initialized at 00 UTC on 27 August 2019, when the TC was approaching the island of Barbados. The forecasts were run for $168 \mathrm{~h}$. All 80 members use the same surface analysis from the GFS analysis, including sea surface temperature (SST). Currently, HAFS-globalnest is not coupled to an ocean model to account for dynamic ocean cooling, although that capability is in development. 


\section{Results}

\subsection{General Ensemble Results}

\subsubsection{Track/Intensity Comparison between All Members}

Figure 2 shows the track and intensity forecasts from all 80 ensemble members analyzed in this study. There were a wide range of track outcomes, ranging from a turn east of the Bahamas to a landfall in the Florida Peninsula. A later study will examine synoptic influences on the longer-range track (near the Bahamas and Florida) in these simulations. This study will focus on the observed track that was mostly outside of the ensemble group in the early part of the forecast period. This bias was seen in several operational ensemble systems as well, including the GFS ensemble (which was used for the initialization of this set) and even the European Center for Medium-Range Weather Forecasting (ECMWF) ensemble (not shown). The intensity forecasts showed a large range, with some members keeping the TC as a weak tropical storm for several days, with others more correctly showing the intensification into a major hurricane. Although the middle of the ensemble group was generally too weak throughout the period, several members did capture the early intensification, and these members will be the focus of detailed analyses for much of the paper. As will be discussed in the next section, the weak bias of the ensemble mean may also be connected to the fact that the ensemble mean track was west of the Best Track, given the relationship between track and intensity that will be discussed.

\subsubsection{Correlation between Track and Intensity Errors}

A later study of this ensemble set will be examined in detail in terms of the synopticscale influences on Dorian's track, and which factors were most important for causing the storm to stall in the Bahamas rather than continuing westward into Florida. Here, we focus on the relationship between the early intensification and the track during this time period $(0-48 \mathrm{~h})$. Figure 3 shows the correlation between cross-track errors and intensity errors at each forecast hour. Note that the intensity bias is used to represent the intensity error, such that negative bias indicates a forecast that was too weak.

From hours 42 to 96 , there is a statistically significant relationship (based on a $t$-test), with members that were too weak having larger cross-track errors. As can be seen in Figure 2, this result means that weaker members were too far southwest compared to the stronger members which were farther northeast and closer to the Best Track. Some of this relationship is partially due to the effects of land interaction with Puerto Rico and Hispaniola - tracks that were further northeast had less land interaction and therefore provided more opportunity for the TC to strengthen. However, the track and intensity relationship was already apparent even before the period of land interaction (around hours $36-42$ ), as can be seen in the track plots with intensity overlaid in this time period (Figure 4). The next section will explore some of the key large-scale factors that led to this relationship between track and intensity in this early period. 
a)

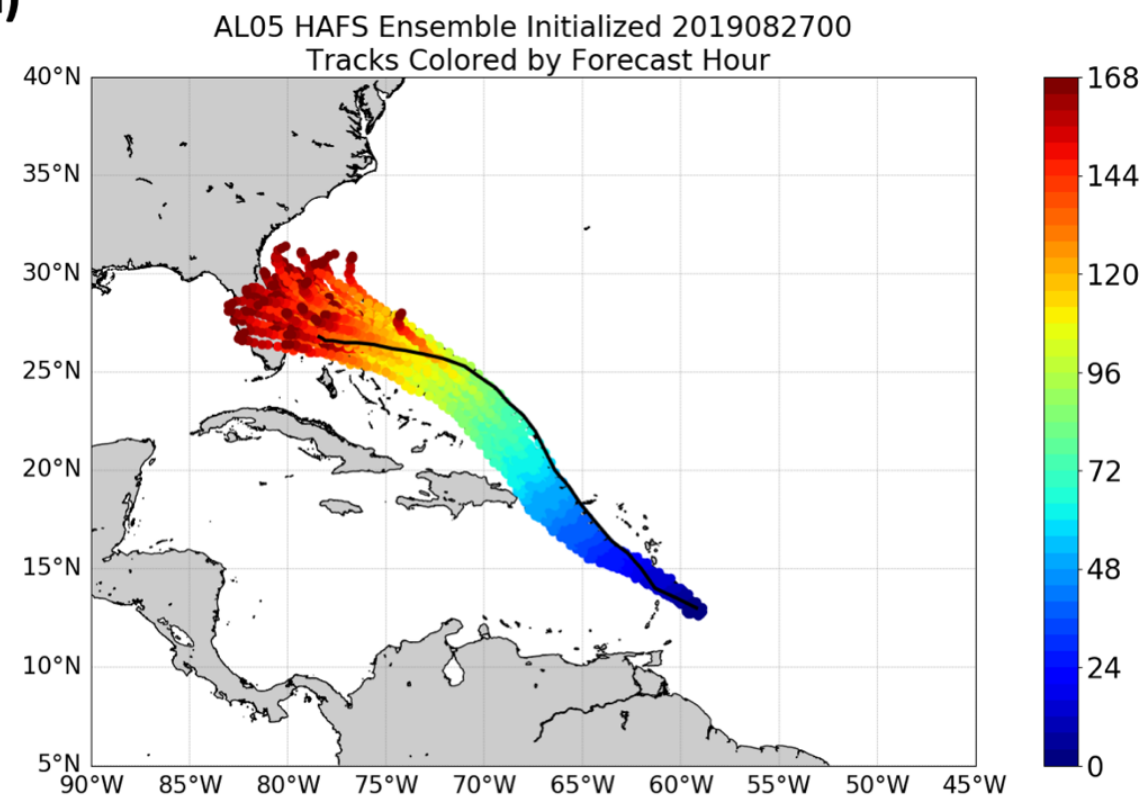

b)

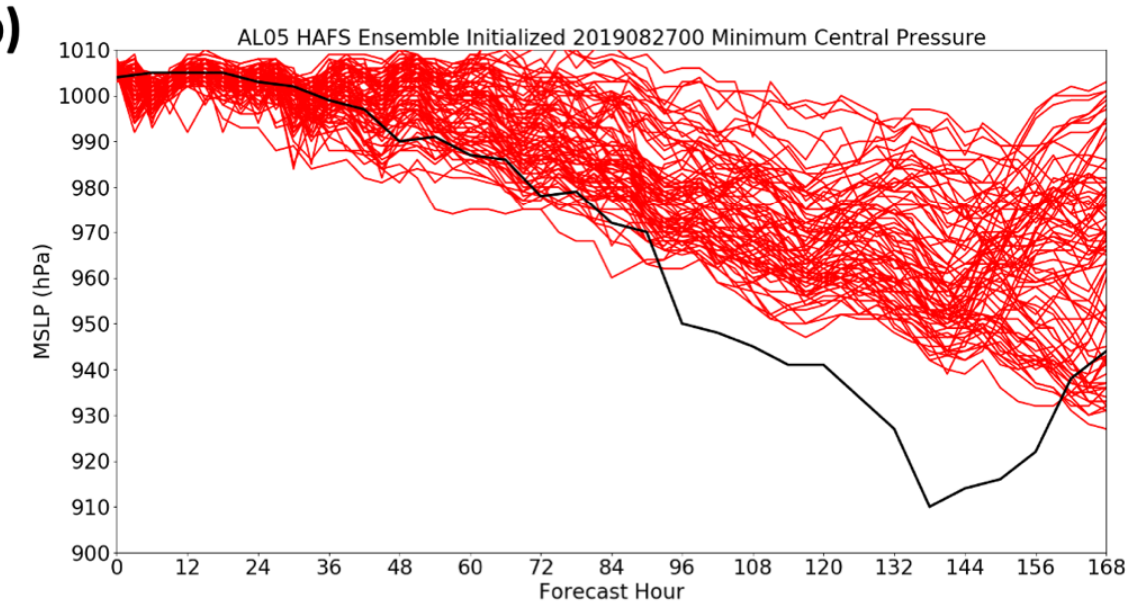

c)

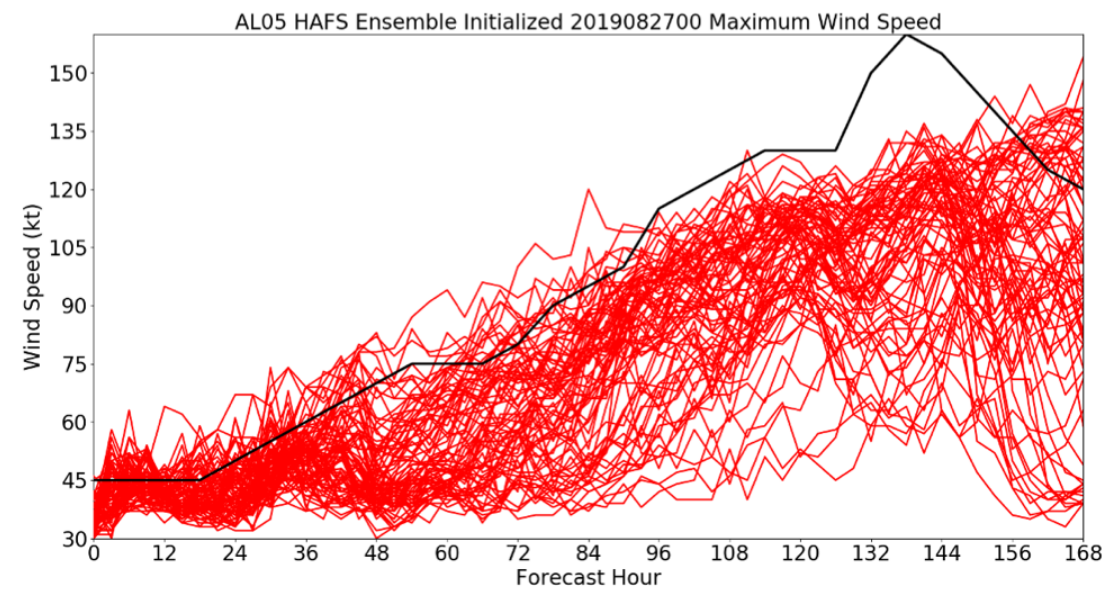

Figure 2. (a) Tracks of all 80 members in the HAFS ensemble initialized at 00 UTC 27 August 2019, run for $168 \mathrm{~h}$. The colors are the forecast hour. The Best Track is shown in black. (b) Intensity (minimum pressure, $\mathrm{hPa}$ ) of all 80 members, run for $168 \mathrm{~h}$. (c) As in (b), but for maximum sustained wind speed $\left(\mathrm{kt}, 1 \mathrm{kt}=0.51 \mathrm{~ms}^{-1}\right)$. The Best Track is shown in black. 


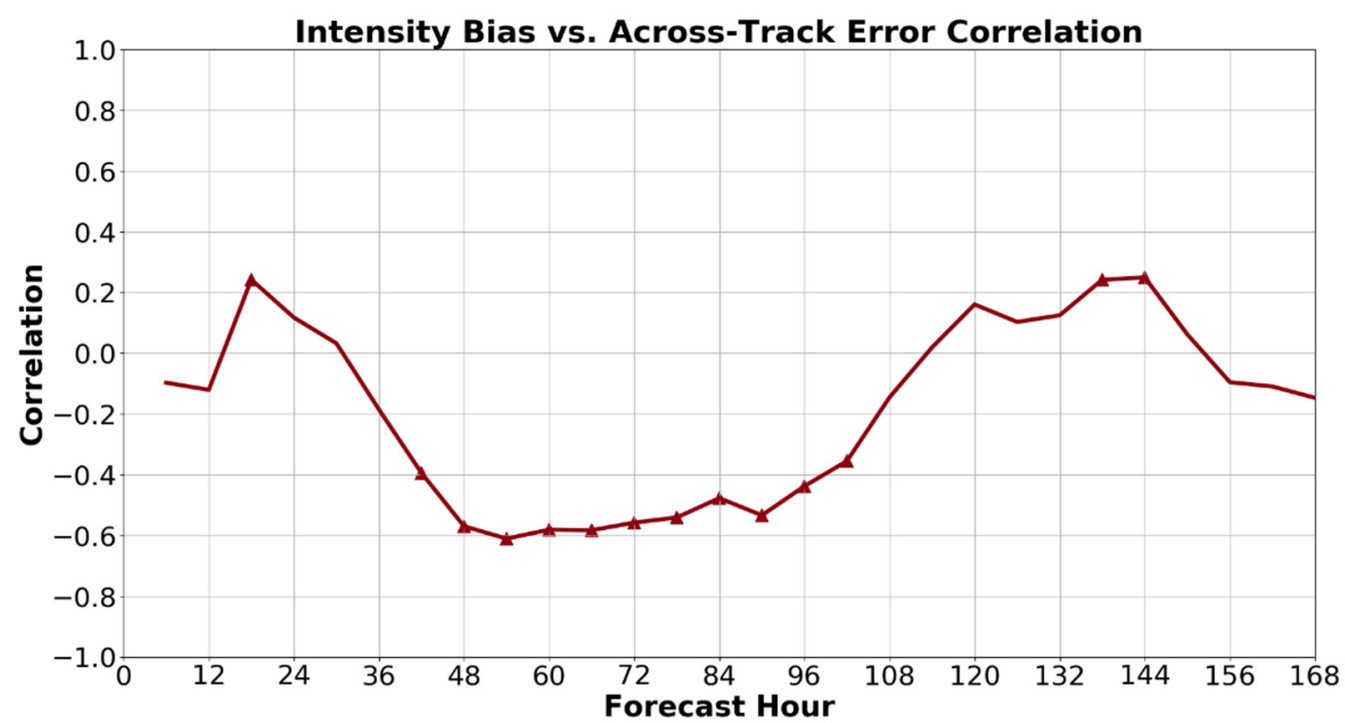

Figure 3. Correlation coefficient between across-track errors and intensity bias at each forecast hour from the ensemble set. Negative correlation means that larger cross-track errors are correlated with a weak intensity bias, and positive correlation means that larger cross-track errors are correlated with a strong intensity bias. The triangles indicate forecast hours where the relationship was statistically significant $(p<0.05)$.

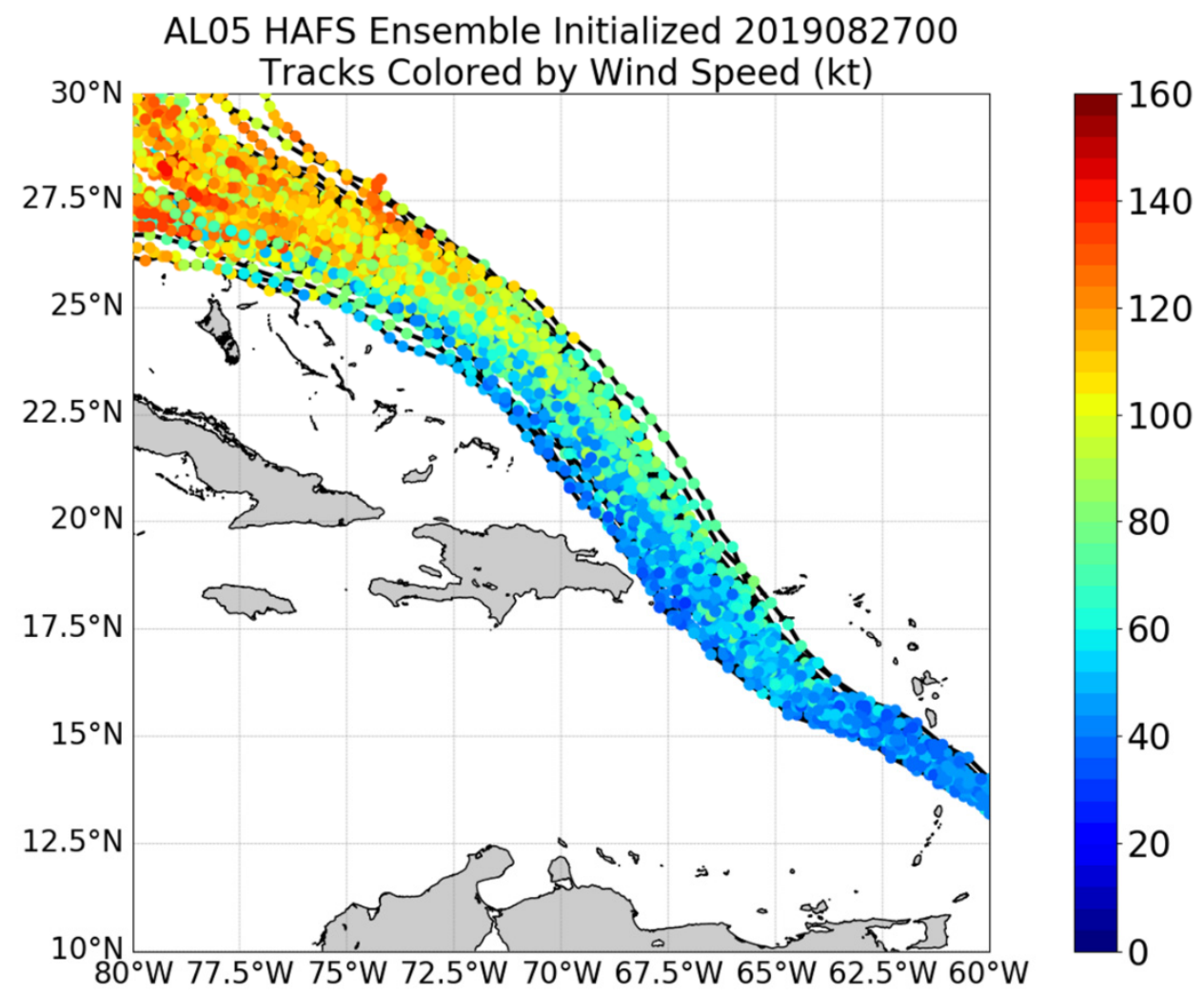

Figure 4. Storm tracks from all 80 ensemble members, zoomed in on the northeast Caribbean region. The tracks are shaded by maximum wind speed in $\mathrm{kt}\left(1 \mathrm{kt}=0.51 \mathrm{~m} \mathrm{~s}^{-1}\right)$.

\subsection{Synoptic Influences on Early Intensity and Track}

3.2.1. Examination of Environmental Variables and Correlation with Early Intensity

Next, the ensemble data is used to explore some of the key early factors that allowed Dorian to intensify in the early period. The "early intensity" is defined as the intensity 
at $42 \mathrm{~h}$, which was right before many members passed over or near Puerto Rico and Hispaniola. This allowed for the early intensity to be examined without the complicating influences of land interaction (which certainly played a role in some members after this early period). The first analysis involved examination of a number of synoptic-scale environmental variables that were calculated from the ensemble data, and their relationship with the intensity at $42 \mathrm{~h}$. These variables are similar to those used to drive the Statistical Hurricane Intensity Prediction Scheme (SHIPS) [24], and are listed in Table 1. The linear correlations between each of these variables at each lead time from 0 to $42 \mathrm{~h}$ and the intensity (minimum pressure) at $42 \mathrm{~h}$ are shown in Figure 5. Even at this early time, there was a large spread in forecast intensity, with the minimum pressure in the members ranging from $982 \mathrm{hPa}$ to $1009 \mathrm{hPa}$. Several interesting patterns stand out from the correlation. First, almost all of the variables show little correlation at early lead time ( $\sim 0$ to $6 \mathrm{~h}$ ), indicating that differences in the environment at model initialization were not directly responsible for the later intensity differences, but the evolution of the environment and TC vortex throughout the forecast was important. It should be noted, however, that some of the variables are likely related (humidity and upper divergence, for example), so it is difficult to fully examine each variable independently. One notable variable that did show a significant relationship was the upper-level zonal wind near the TC, indicative of some difference in upper-level anticyclone structure between the members at the initialization time that will be examined in more detail. The vertical shear at early lead times was not well-correlated with intensity at $42 \mathrm{~h}$, but the relationship improved closer to that forecast hour as the environment around the TC evolved. The variables that were most significantly correlated with intensity at $42 \mathrm{~h}$, with $12-24 \mathrm{~h}$ lead time, were the moisture (in all layers), the upperlevel divergence, and the mid-level $(850-500 \mathrm{hPa})$ shear. These correlations generally peaked at around $12-30 \mathrm{~h}$, suggesting that this period after spin-up was key to determining the intensity and structure of Dorian in the different members.

Table 1. Large-Scale Environmental Variables Calculated From the HAFS Ensemble Data.

\begin{tabular}{|c|c|c|}
\hline Variable & Variable Description & Variable Definition \\
\hline SHRD & $\begin{array}{l}\text { Deep-layer vertical } \\
\text { wind shear }\end{array}$ & $\begin{array}{l}\text { 850-200 } \mathrm{hPa} \text { Wind Shear }(\mathrm{kt}) \\
\text { Calculated in an annulus } 200-800 \mathrm{~km} \text { from the tropical cyclone center }(\mathrm{r}=200-800)\end{array}$ \\
\hline SHRS & Mid-level vertical wind shear & $\begin{array}{l}850-500 \text { hPa Wind Shear }(\mathrm{kt}) \\
(\mathrm{r}=200-800)\end{array}$ \\
\hline RHHI & Upper-level humidity & Relative humidity (\%) Averaged over the 500-300 hPa Layer $(r=200-800)$ \\
\hline RHMD & Mid-level humidity & Relative humidity (\%) Averaged over the $700-500 \mathrm{hPa}$ Layer $(\mathrm{r}=200-800)$ \\
\hline RHLO & Low-level humidity & Relative humidity (\%) Averaged over the 850-700 hPa Layer $(\mathrm{r}=200-800)$ \\
\hline D200 & Upper-level divergence & Divergence $\left(\mathrm{s}^{-1}\right)$ at $200 \mathrm{hPa}(\mathrm{r}=200-800)$ \\
\hline U200 & Upper-level Zonal Wind & Zonal wind $(\mathrm{kt})$ at $200 \mathrm{hPa}(\mathrm{r}=200-800)$ \\
\hline U20C & $\begin{array}{l}\text { Upper-level Zonal } \\
\text { Wind Near TC }\end{array}$ & $\begin{array}{l}\text { Zonal wind }(\mathrm{kt}) \text { at } 200 \mathrm{hPa} \text { calculated in a radius } 0-500 \mathrm{~km} \text { from the TC center } \\
\qquad(\mathrm{r}=0-500)\end{array}$ \\
\hline V20C & $\begin{array}{l}\text { Upper-level Meridional } \\
\text { Wind Near TC }\end{array}$ & Meridional wind $(\mathrm{kt})$ at $200 \mathrm{hPa}(\mathrm{r}=0-500)$ \\
\hline PENV & Environmental sea-level pressure & Mean sea level pressure $(r=200-800)$ \\
\hline
\end{tabular}

The SHIPS-like variables are useful for assessing the overall importance of large-scale synoptic factors, but because of the large spatial averaging involved, it can be difficult to ascertain the exact nature of the large-scale features responsible for influencing the TC intensity [9]. Thus, the structure of the synoptic environment early in the lifecycle of Dorian is examined next. In order to tease out the relationship with intensity change, composites of the 20 strongest and 20 weakest members (as defined by the minimum pressure at $42 \mathrm{~h}$ ) are compared. Figure 6 shows the differences in 200-hPa height between the strong composite and the weak composite, as well as the difference in the composite 
wind vectors, at $0 \mathrm{~h}$ (initialization), $24 \mathrm{~h}$ (near when most variables showed peak correlation with $42 \mathrm{~h}$ intensity), and $42 \mathrm{~h}$. There are clear differences even at the initial time, with the strong group having a much stronger anticyclone to the north and east of the TC center. This difference is significant based on a $t$-test. The vector difference shows that there is stronger upper-level divergence in this region (including at/near the TC center), and the upper-level low pressure area to the north of the TC is weaker at initialization in the strong group (see a later section for an individual example from two members). As time went on, this difference in the upper-level fields became even more pronounced, with a stronger upper-level anticyclone over and especially to the east of the TC center in the strong group, and a weaker upper-level low due north of the TC (as seen in the dipole pattern in Figure 6c). This difference in the upper-level wind and height fields was clear at the initial time and grew with time in the forecasts, with an apparent positive feedback between the upper divergence and convection on the north and east sides of the TC. This difference is also reflected in the mid-to-upper-level moisture field (Figure 7). There is slightly higher moisture initially to the northeast of the TC center in the strong composite, seemingly coupled with the area of stronger upper divergence. As time went on, this difference became more pronounced. Interestingly, while the strong group has higher overall humidity due to the large difference on the east side, the strong group also has a pronounced area to the southwest where there is lower humidity. This implies a preferred location for convection to the northeast in the strong group, and to the southwest in the weak group, which will be seen in the individual members examined later.

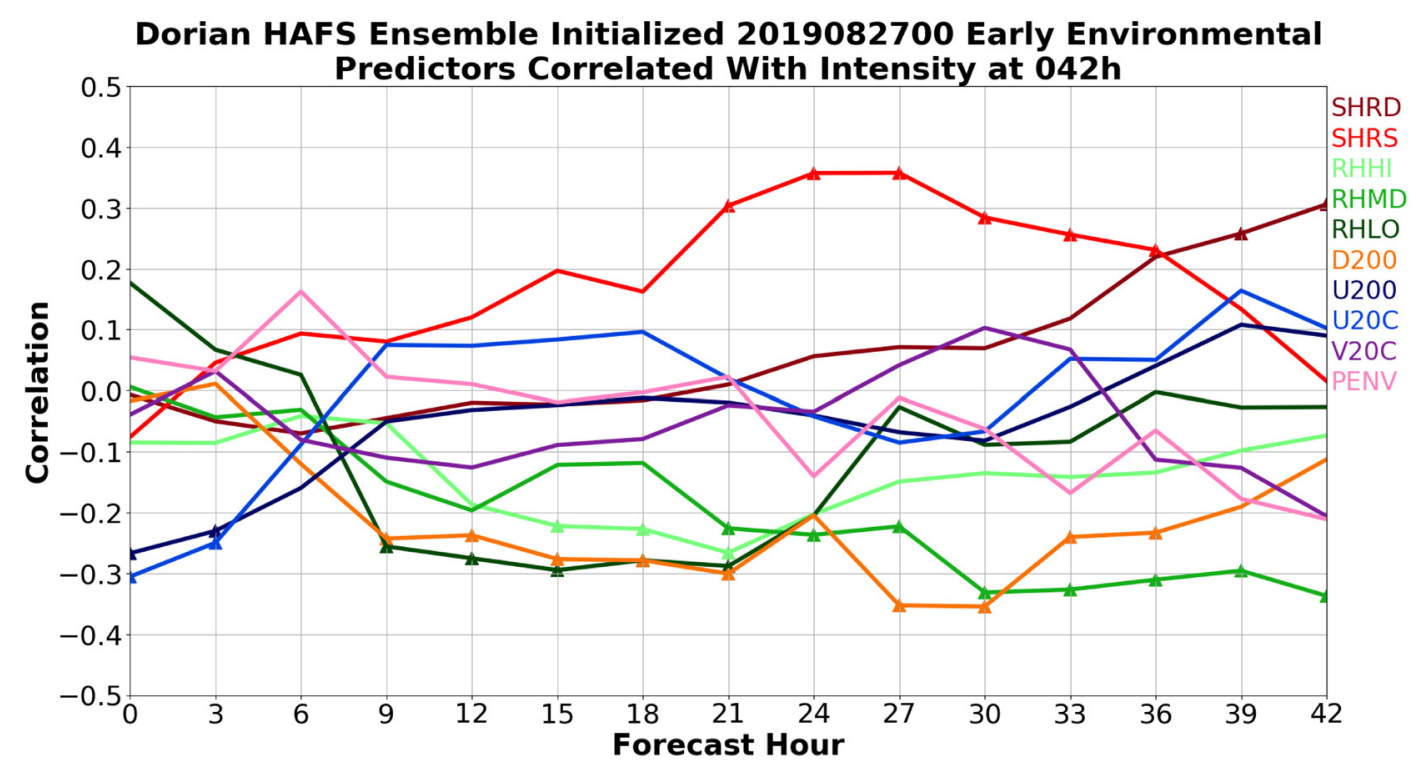

Figure 5. Correlations between all environmental predictors from 0 to $42 \mathrm{~h}$ with the $42 \mathrm{~h}$ intensity (minimum pressure) of Dorian. Positive correlation indicates that a higher value of the variable leads to a weaker storm. Forecast hours when the correlation is statistically significant $(p<0.05)$ are shown with the triangles.

\subsubsection{Examination of Structural Variables and Correlation with TC Intensity}

The above analysis highlighted some of the composite synoptic variables that were important for the early evolution of Dorian. Next, some of the storm-scale structural metrics that have been shown to be important for other TCs were examined to see which ones correlated with the intensity of the TC in the ensemble members. For this analysis, a precipitation partitioning algorithm was used that has been applied to radar data in several previous studies $[25,26]$ to distinguish between stratiform and convective precipitation. The algorithm also sorts convective precipitation into shallow, moderate, and deep convection based on height and reflectivity thresholds. Originally developed by Steiner et al. [27], the partitioning algorithm has also been applied to numerical model output by Rogers [28]. 
As in that study, some adjustments to several thresholds and tuning parameters were made due to differences in model simulated reflectivity and observed reflectivity from aircraft data. These differences can include model bias as well as attenuation in the aircraft radar observations. Table 2 lists several key height and reflectivity thresholds used in the model, and compares this with the radar method of Steiner et al. [27]. The radar thresholds are also applied to the observed NOAA P-3 aircraft radar data used for comparison with the model data.
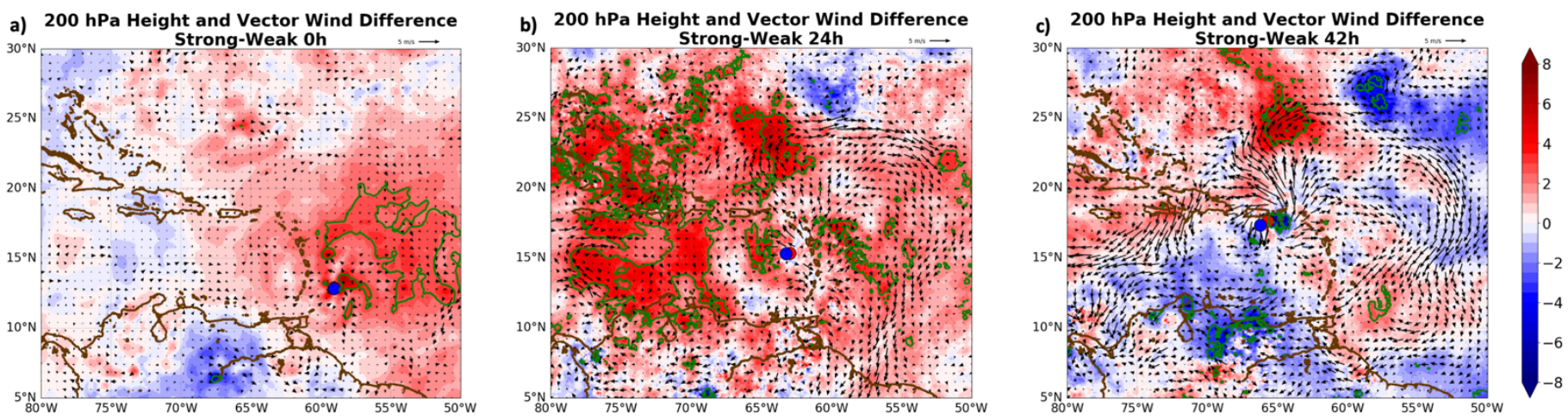

Figure 6. (a) 200-hPa height difference (m, shaded) between the composite of the 20 strongest members and 20 weakest members (based on minimum pressure at $42 \mathrm{~h}$ ) at $0 \mathrm{~h}$ (initialization). The green contours highlight areas that have a statistically significant difference $(p<0.05)$. The vectors show the difference in the composite vector winds between the strong and weak groups. The red and blue circles show the mean positions of the strong and weak groups. (b) As in (a), but for the $24 \mathrm{~h}$ forecast. (c) As in (b), but for the $42 \mathrm{~h}$ forecast.
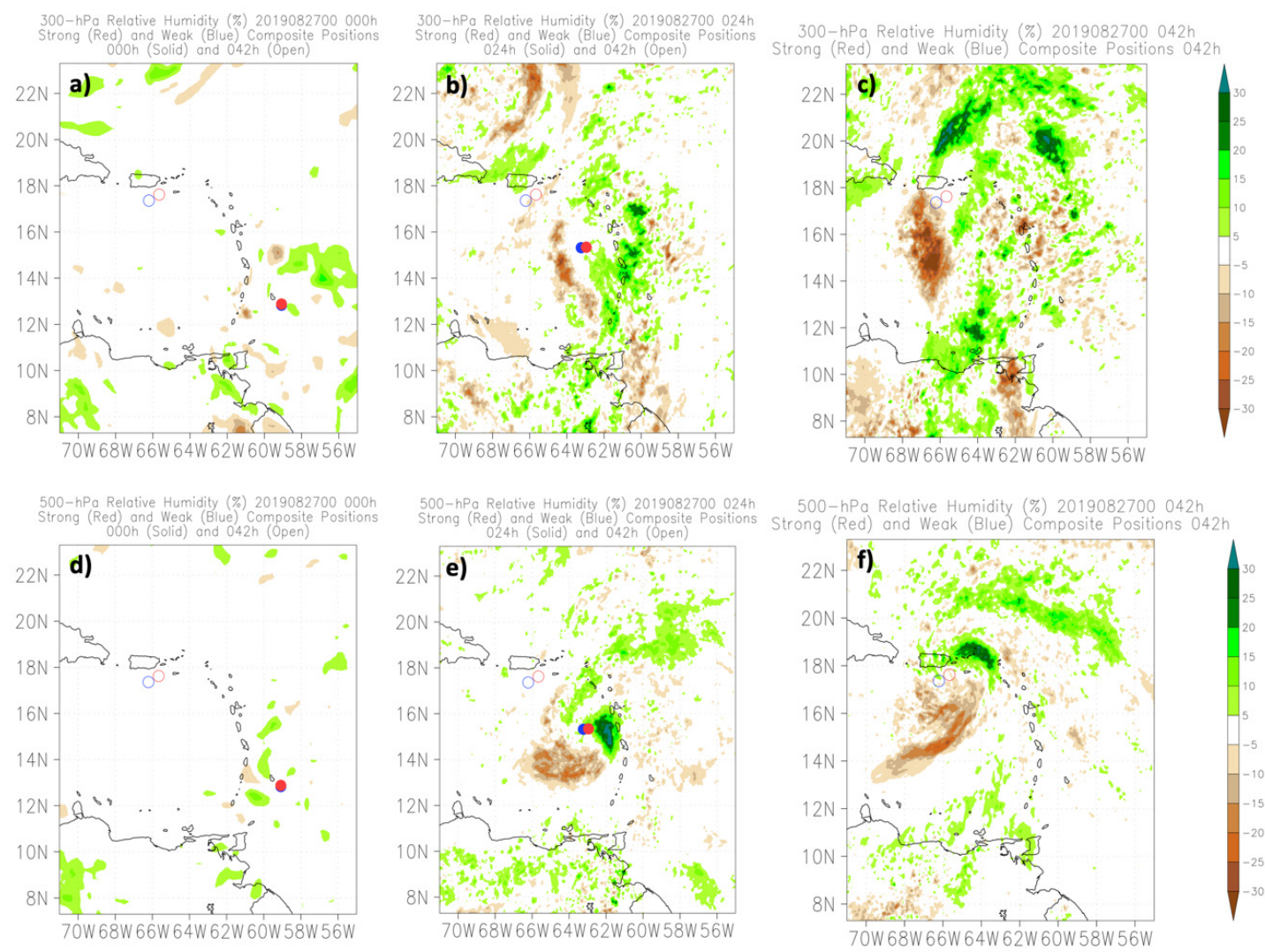

Figure 7. (a) 300-hPa relative humidity (\%) difference between the composite of the 20 strongest members and 20 weakest members (based on minimum pressure at $42 \mathrm{~h}$ ) at $0 \mathrm{~h}$ (initialization). The solid circles show the mean position of the strong group (red) and weak group (blue) at $0 \mathrm{~h}$, and the open circles show the positions at $42 \mathrm{~h}$. (b) As in (a), but at $24 \mathrm{~h}$. (c) As in (a), but at 42 h. (d) As in (a), but for 500-hPa relative humidity. (e) As in (d), but at $24 \mathrm{~h}$. (f) As in (d), but at $42 \mathrm{~h}$. 
Table 2. Parameters for the Precipitation Partitioning Algorithm.

\begin{tabular}{ccc}
\hline Parameter & Model Value & Radar Value \\
\hline Height Initially Analyzed & $2 \mathrm{~km}$ & $2 \mathrm{~km}$ \\
\hline Convective Reflectivity Threshold & $50 \mathrm{dBZ}$ & $40 \mathrm{dBZ}$ \\
\hline Stratiform Reflectivity Threshold & $20 \mathrm{dBZ}$ & $20 \mathrm{dBZ}$ \\
\hline “Convective peak” Tuning Parameter & $55 \mathrm{dBZ}$ & $45 \mathrm{dBZ}$ \\
\hline Height Threshold for Moderate Convection & $6 \mathrm{~km}$ & $6 \mathrm{~km}$ \\
\hline Height Threshold for Deep Convection & $10 \mathrm{~km}$ & $10 \mathrm{~km}$ \\
\hline Echo Top Reflectivity Threshold & $30 \mathrm{dBZ}$ & $20 \mathrm{dBZ}$ \\
\hline
\end{tabular}

In this analysis, we examine time series of the evolving inner-core precipitation structure. To do this, a metric chosen is eyewall closure, similar to that discussed in Matyas et al. [29] and Hazelton et al. [14]

$$
\text { Closure }=\frac{\sum_{0^{\circ}}^{360^{\circ}} \alpha(\text { if ptype } \geq \text { threshold })}{\sum_{0^{\circ}}^{360^{\circ}} \alpha}
$$

The threshold is based on the integer value of the precipitation type in the algorithm (one for weak echo, two for stratiform, three for shallow convection, four for moderate convection, five for deep convection). Thus, a closure of one indicates a perfectly closed ring, and a closure of zero indicates no precipitation meeting the required threshold. The region analyzed is the eyewall, defined as $\mathrm{r}^{*}=0.75 \mathrm{RMW}_{2 \mathrm{~km}}$ to $\mathrm{r}^{*}=1.25 \mathrm{RMW}_{2 \mathrm{~km}}$ (as in Rogers et al. [30] and Hazelton et al. [31]). $\mathrm{RMW}_{2} \mathrm{~km}$ is the azimuthal mean radius of maximum winds at 2-km altitude.

A few other dynamic and thermodynamic variables were also examined. The local Rossby number is related to both the size and magnitude of the incipient vortex [32], and is defined as

$$
\text { Ross }=\frac{\left.V_{t}\right|_{R M W_{10 \mathrm{~m}}}}{f * R M W_{10 \mathrm{~m}}}
$$

$\left.V_{t}\right|_{R M W_{10 \mathrm{~m}}}$ is the tangential wind at the 10-m RMW, $R M W_{10 \mathrm{~m}}$ is the 10-m RMW (similar to but usually slightly different from the 2-km RMW due to eyewall slope [33]), and $f$ is the Coriolis parameter. Another variable examined is the magnitude of the innercore temperature anomaly, which is related to the developing TC warm core and defined similarly to Zhang et al. [34] as

$$
T M P A=\operatorname{MAX}\left(\overline{T_{0-15}}-\overline{T_{200-300}}\right)
$$

$T_{0-15}$ is the temperature in the $0-15 \mathrm{~km}$ radius from the TC center, while $T_{200-300}$ is the temperature in the $200-300 \mathrm{~km}$ radius from the TC center. The warm core magnitude is taken as the maximum of this difference in the $0-18 \mathrm{~km}$ vertical layer. A final dynamic variable examined is the vortex tilt. The tilt is examined in two layers, $2-5 \mathrm{~km}$ and $2-10 \mathrm{~km}$, with the center defined based on the vorticity centroid at each height. Table 3 lists the structural variables examined, including their abbreviations and definitions. 
Table 3. Storm-scale structure variables calculated from the HAFS ensemble data.

\begin{tabular}{|c|c|c|}
\hline Variable & Variable Description & Variable Definition \\
\hline PWEI & $\begin{array}{l}\text { Percentage of the area in the eyewall that } \\
\text { has weak echoes }\end{array}$ & $\begin{array}{c}\text { Percentage of the area from } r^{*}=0.75-1.25 \text { that has weak echoes based on } \\
\text { the precipitation partitioning algorithm }\end{array}$ \\
\hline PSTI & $\begin{array}{l}\text { Percentage of the area in the eyewall that } \\
\text { is stratiform precipitation }\end{array}$ & $\begin{array}{l}\text { Percentage of the area from } \mathrm{r}^{*}=0.75-1.25 \text { that has stratiform } \\
\text { precipitation based on the precipitation partitioning algorithm }\end{array}$ \\
\hline PSHI & $\begin{array}{l}\text { Percentage of area in the eyewall that is } \\
\text { shallow convection }\end{array}$ & $\begin{array}{l}\text { Percentage of the area from } r^{*}=0.75-1.25 \text { that has shallow convection } \\
\text { based on the precipitation partitioning algorithm }\end{array}$ \\
\hline PMOI & $\begin{array}{l}\text { Percentage of area in the eyewall that is } \\
\text { moderate convection }\end{array}$ & $\begin{array}{l}\text { Percentage of the area from } \mathrm{r}^{*}=0.75-1.25 \text { that has moderate convection } \\
\text { based on the precipitation partitioning algorithm }\end{array}$ \\
\hline PDEI & $\begin{array}{l}\text { Percentage of area in the eyewall that is } \\
\text { deep convection }\end{array}$ & $\begin{array}{c}\text { Percentage of the area from } r^{*}=0.75-1.25 \text { that has deep convection based } \\
\text { on the precipitation partitioning algorithm }\end{array}$ \\
\hline CLST & $\begin{array}{l}\text { Closure of the eyewall by } \\
\text { stratiform precipitation }\end{array}$ & $\begin{array}{c}\text { Percentage of the eyewall enclosed by at least one grid point of stratiform } \\
\text { precipitation based on the precipitation partitioning algorithm }\end{array}$ \\
\hline CLSH & $\begin{array}{l}\text { Closure of the eyewall by } \\
\text { shallow convection }\end{array}$ & $\begin{array}{l}\text { Percentage of the eyewall enclosed by at least one grid point of shallow } \\
\text { convection precipitation based on the precipitation } \\
\text { partitioning algorithm }\end{array}$ \\
\hline CLMO & $\begin{array}{l}\text { Closure of the eyewall by } \\
\text { moderate convection }\end{array}$ & $\begin{array}{l}\text { Percentage of the eyewall enclosed by at least one grid point of moderate } \\
\text { convection based on the precipitation partitioning algorithm }\end{array}$ \\
\hline CLDE & $\begin{array}{l}\text { Closure of the eyewall by } \\
\text { deep convection }\end{array}$ & $\begin{array}{l}\text { Percentage of the eyewall enclosed by at least one grid point of deep } \\
\text { convection based on the precipitation partitioning algorithm }\end{array}$ \\
\hline RMW2 & Radius of Maximum Winds at $\mathrm{z}=2 \mathrm{~km}$ & Radius of maximum azimuthal-mean 2-km tangential wind \\
\hline ROSS & Local Rossby Number & See Equation (2) \\
\hline TMPA & Inner-core temperature anomaly & $\begin{array}{l}\text { The maximum temperature difference between the average in the } \\
\qquad 0-15 \mathrm{~km} \text { radius and the } 200-300 \mathrm{~km} \text { annulus }\end{array}$ \\
\hline TMVM & Mid-level vortex tilt & Vortex tilt based on vorticity centers at $2 \mathrm{~km}$ and $5 \mathrm{~km}$ \\
\hline TMVD & Deep-level vortex tilt & Vortex tilt based on vorticity centers at $2 \mathrm{~km}$ and $10 \mathrm{~km}$ \\
\hline
\end{tabular}

Figure 8 shows the correlations between these structural metrics and the $42 \mathrm{~h}$ intensity of the TC in the ensemble members, again defined as the minimum central pressure.

Unsurprisingly, the precipitation organization, vortex strength, and warm core anomaly all correlated strongly (and statistically significantly) with the intensity at 0 lead (42 h). As with the synoptic variables, though, several variables show strong relationships at earlier leads. In particular, the percentages/closure of moderate and deep convection at hours 015 and onward are strongly correlated with the $42 \mathrm{~h}$ TC intensity. Similarly, the Rossby number and warm-core magnitude around this time $(15 \mathrm{~h})$ is well-correlated with the intensity over a day later. This further highlights that, in addition to the large-scale differences, vortex-scale and convective structural differences between members were critical in determining the evolution in the Eastern Caribbean. Inner-core structure has been shown to be a critical component of RI onset in moderately-sheared environments. A decrease of $\mathrm{RMW}_{10 \mathrm{~m}}$, which leads to a larger Rossby number, is one such structural change that has been linked to RI onset [32]. Precipitation symmetry has also been shown to be a critical part of conditioning a vortex for rapid intensification [35,36], and these relationships imply that was true in the early intensification of Dorian. There is also a strong relationship $(r=0.88)$ between the initial intensity in the simulations and the intensity at $42 \mathrm{~h}$, implying that some of the structure differences (and perhaps some of the large-scale initial differences discussed above) were tied to the initial state of the TC. More details of the structural evolution are highlighted in the comparison of two members in the next section. 
a)

Dorian HAFS Ensemble Initialized 2019082700 Early Precipitation Structure

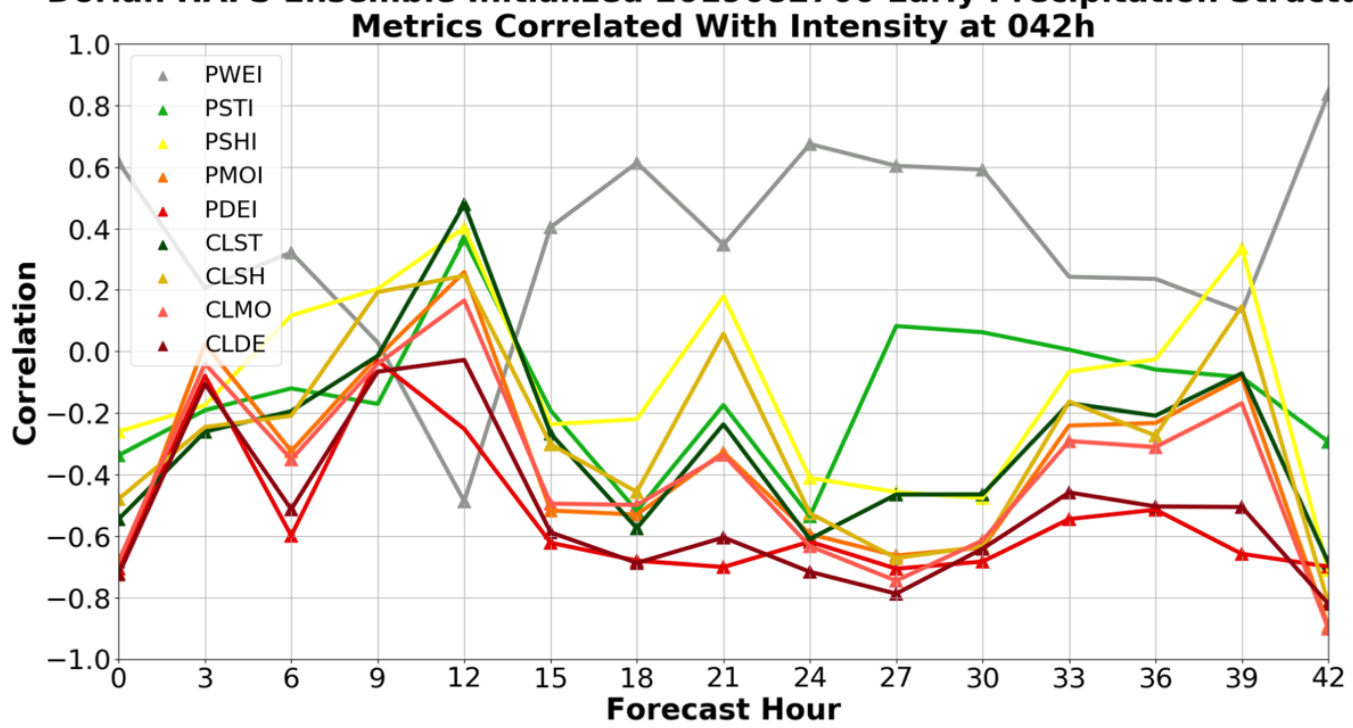

b) Dorian HAFS Ensemble Initialized 2019082700 Early Dynamic Structure

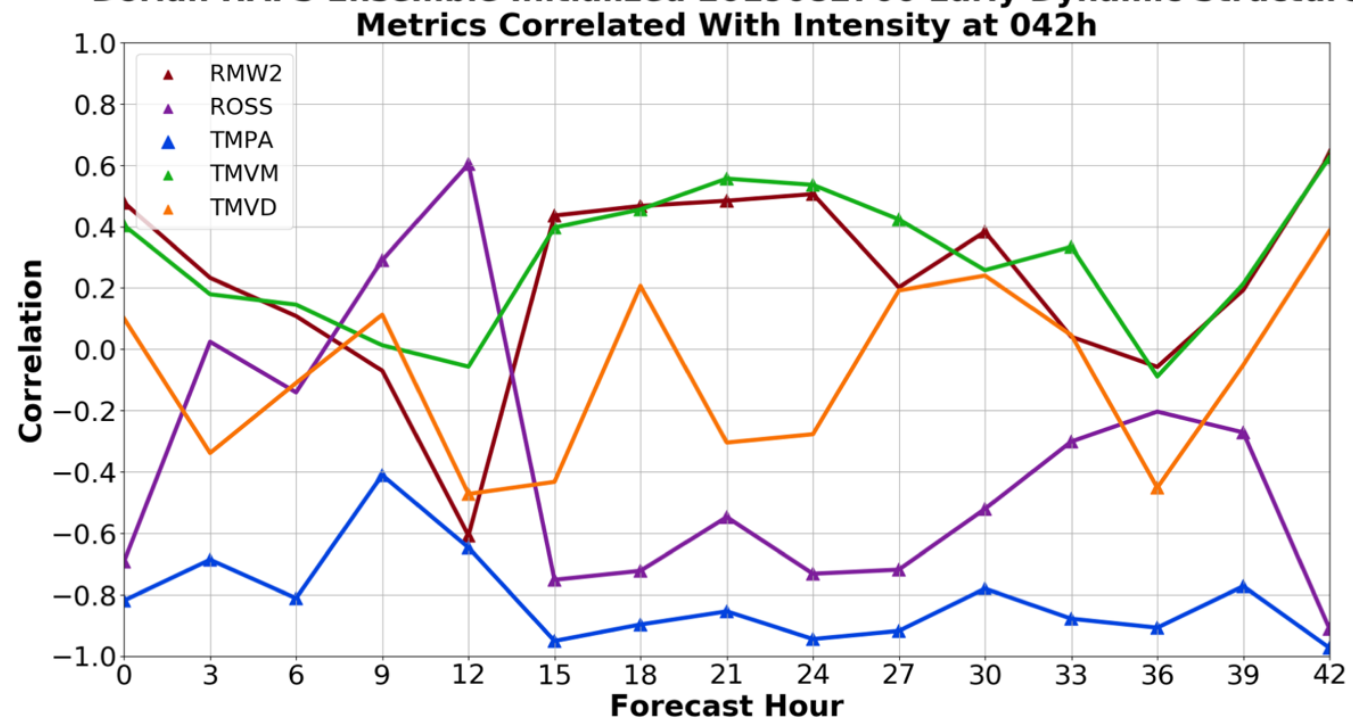

Figure 8. Correlations between all structure metrics from 0 to $42 \mathrm{~h}$ with the intensity (minimum pressure) of Dorian at $42 \mathrm{~h}$. Forecast hours where the correlation is statistically significant $(p<0.05)$ are shown with the triangles.

\subsection{Detailed Examination of Two Divergent Members}

In order to further explore the details of the synoptic and vortex-scale factors that were responsible for Dorian's evolution in the period of its lifecycle near the Antilles, two individual members are next examined in detail.

\subsubsection{Track/Intensity Comparison between Two Members}

Figure 9 shows the tracks of the two members as well as Best Track. One of the members, member 57 (the "weak member"), was an outlier on the weak and southwest side of the ensemble envelope, showing very little development in the first few days and passing between Puerto Rico and Hispaniola. This was similar to the forecast from several operational and experimental models at this point during Dorian's lifecycle (not shown). On the other hand, member 72 (the "strong member") was on the right side of the ensemble envelope, one of a few members to predict a track that was close to the observed path. It was also one of the stronger members during this early time period, correctly predicting intensification as the TC moved to the northwest and passed over St. Croix and east of 
Puerto Rico. As shown in Figure 9, the track and intensity of the strong member was very close to the "Best Track" for this early period. The fact that neither of these members was directly impacted by a large land mass during this period also helps with the analysis of the processes responsible for intensity change.

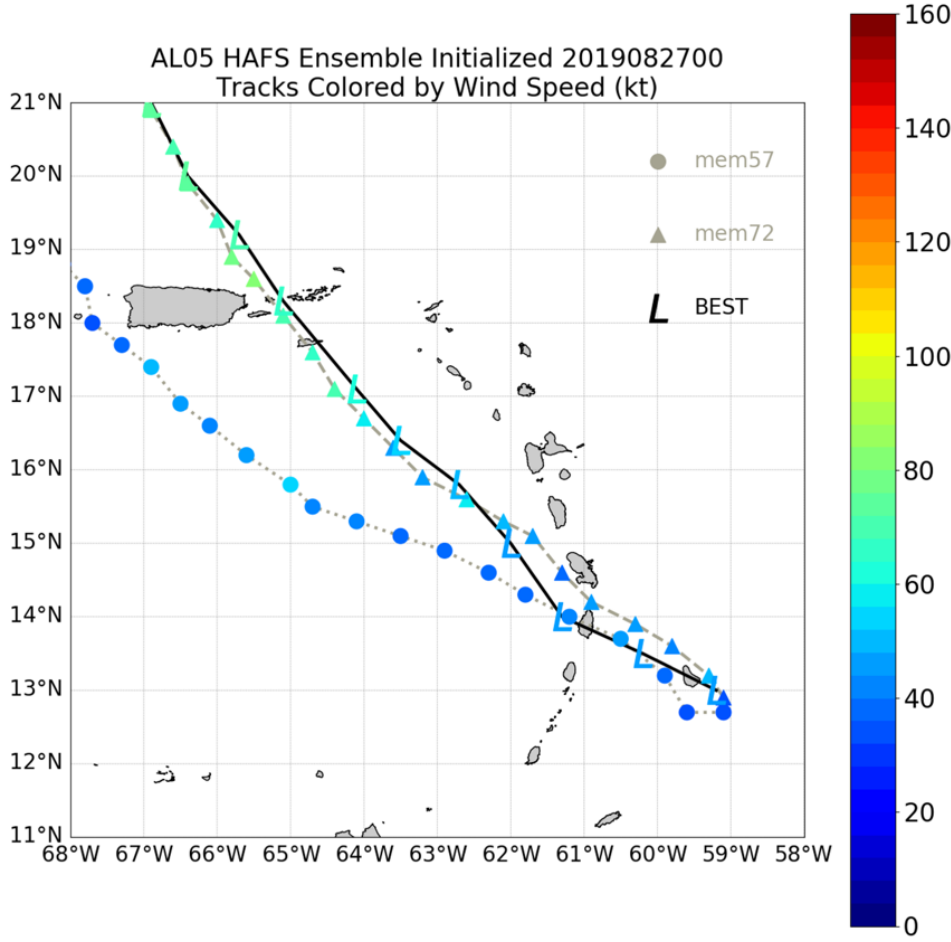

Figure 9. Tracks from the weak member (gray line with circles) and strong member (gray line with triangles) in the early forecast period in the northeast Caribbean. The observed track from Best Track is shown on the black line with "L" symbols. The tracks are shaded by maximum wind speed in kt $\left(1 \mathrm{kt}=0.51 \mathrm{~m} \mathrm{~s}^{-1}\right)$.

To provide another illustration of the evolution of intensity in these two members compared to the observed TC, Figure 10 shows the time series of maximum wind speed and minimum central pressure from both members, as well as from the "Best Track" observations. The two members followed each other and the Best Track closely for the first $12 \mathrm{~h}$ of the forecast. However, just after $12 \mathrm{~h}$, a divergence began to occur, with the weak member continuing to stay basically flat in intensity while the pressure began falling and the winds began to increase in the strong member as well as in the observed TC. The rate of intensification was slightly quicker initially in the strong member than observations, with more fluctuations (which is typical of noisier model data) and a slightly different pressure-wind relationship than the observed. However, by the end of this 48-h period the strong member was close in intensity ( $75 \mathrm{kt})$ to the observed intensity $(70 \mathrm{kt})$, while the weak member remained weak (35-40 kt) through the entire forecast period. Looking back at Figure 9, 012-15 h was when the tracks of the two members started to diverge as well. At $12 \mathrm{~h}$ (5th forecast point), both members (and Best Track) showed the center of the TC near St. Lucia. The trajectories of the members diverged from this point forward, however. The coincidence of the divergence in both track and intensity around this point is consistent with the full ensemble results discussed above. The environmental and structural changes leading to this difference are discussed next. 


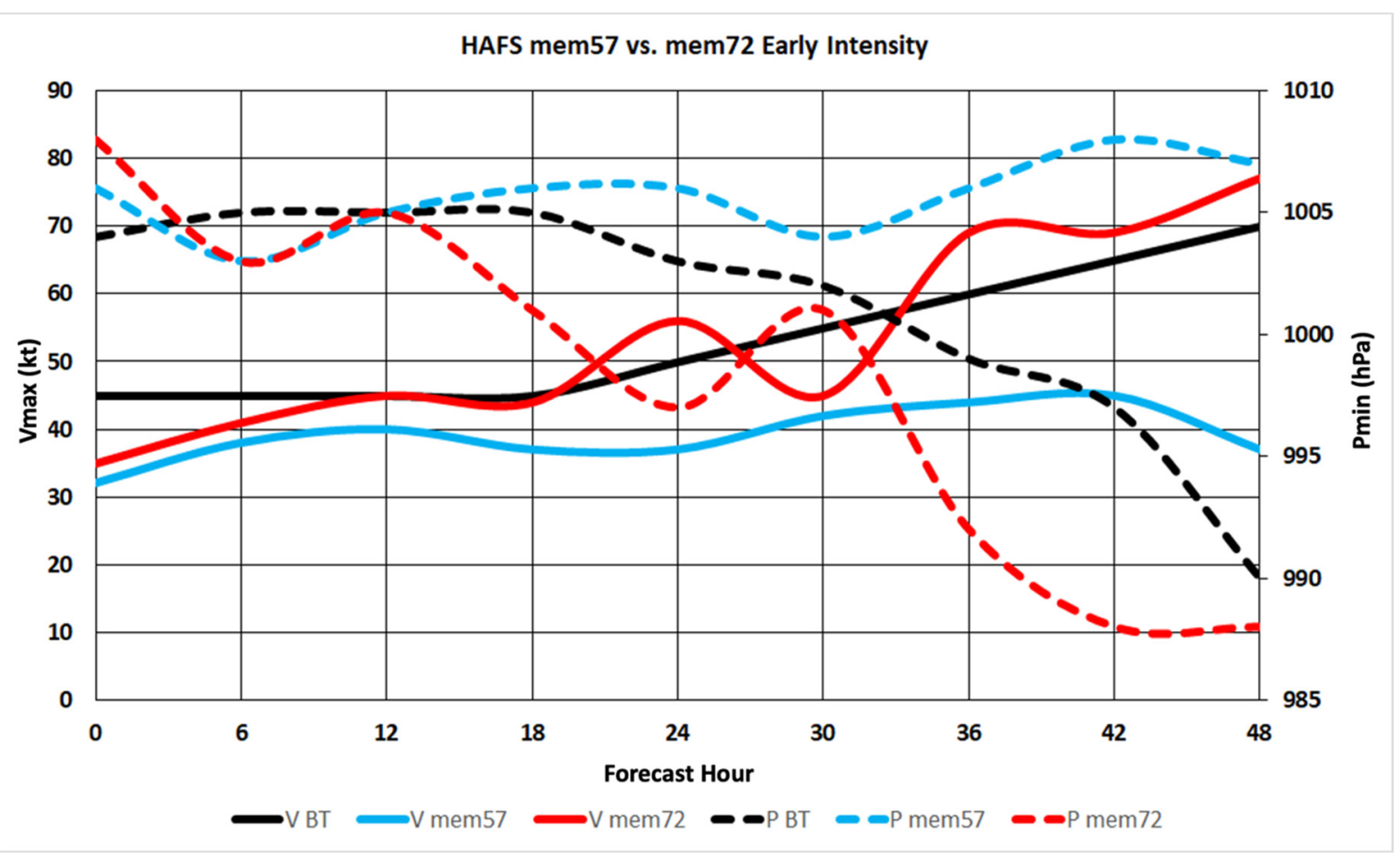

Figure 10. Maximum sustained wind speed $\left(\mathrm{kt}, 1 \mathrm{kt}=0.51 \mathrm{~m} \mathrm{~s}^{-1}\right)$ in the solid lines and minimum central pressure (hPa) in the dashed lines for the weak member (blue), the strong member (red), and Best Track for Dorian (black) from 0 to $48 \mathrm{~h}$ of the simulation. The time series are smoothed for plotting.

\subsubsection{Synoptic Differences between Two Members}

In this section, we dig deeper into the synoptic-scale processes that were responsible for the intensity divergence between the two members. As shown in the composites above, one of the key differences appeared to be the early evolution of the subtropical ridge to the northeast of the storm, and the upper-level low to the northwest. The interplay between these two features, while somewhat subtle, appeared to play a major role in determining the intensity and structural evolution of the TC in the Eastern Caribbean. Figure 11 illustrates this point, showing the 200-hPa height and wind at initialization/0 h, $24 \mathrm{~h}$, and $36 \mathrm{~h}$ for the weak and strong members. While the key synoptic features are similar in both members, the differences in their structures were important. In the strong member, the upper-level low to the north of Dorian was weaker than in the weak member at initialization, and the upper-level anticyclone to the north and east of the TC (around $20 \mathrm{~N}, 50-55 \mathrm{~W}$ ) was stronger at initialization as well. These differences persisted and grew throughout the forecast. This contributed to the slightly stronger environmental shear in the weak member, and the tendency for more precipitation on the east side of the strong member (discussed later), helping the evolving TC circulation to develop closer to the convection on the east side.

As another way of visualizing the large-scale differences between the two members, the 200-hPa potential vorticity (PV) at $24 \mathrm{~h}$ is shown in Figure 12. This variable highlights the key synoptic features impacting Dorian in the early lifecycle. The large-scale pattern was very similar in the two members, but some key subtle differences were apparent, especially in the difference plot (Figure 12c). The PV streamer (upper low) was farther southeast (closer to the TC) in the weak member, and there was a generally larger area of low PV surrounding the TC in the strong member, associated with the larger/stronger upper-level anticyclone seen in the ensemble composites. Both of these differences provided a more favorable environment for convection development in the strong member. The oddity of this point is explored next in a detailed analysis of the shear structure near Dorian in these two members. 

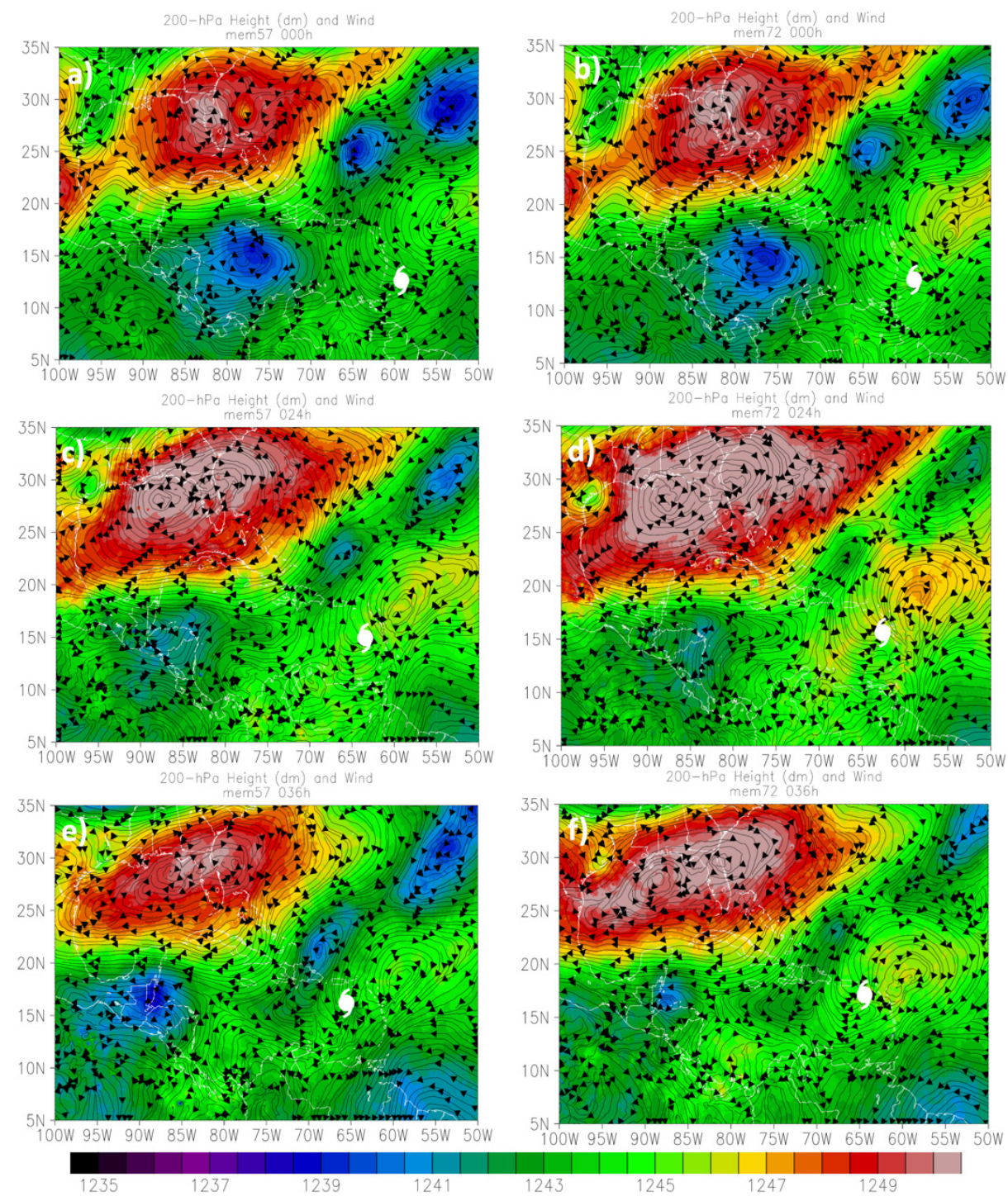

Figure 11. (a) 200-hPa height (dm, shaded) and wind (kt, wind barbs, $1 \mathrm{kt}=0.51 \mathrm{~m} \mathrm{~s}^{-1}$ ) at $0 \mathrm{~h}$ for the weak member. The white hurricane symbol shows the forecast position of Dorian. (b) As in (a), but for the strong member. (c) As in (a), but for $24 \mathrm{~h}$. (d) As in (b), but for $24 \mathrm{~h}$. (e) As in (a), but for $36 \mathrm{~h}$. (f) As in (b), but for $36 \mathrm{~h}$.

Although the upper-level wind fields evolved differently in the strong and weak members, the earlier correlations (Figure 5) also showed that the mid-level shear was a distinguishing factor for the TC intensity as well. Some previous studies have in fact suggested that shallower, mid-troposphere shear can actually be a greater detriment to intensification than deep-layer shear [37]. Figure 13 shows the mid-level $(850-500 \mathrm{hPa})$ shear in the two members in the area near and around the TC, at initialization and $24 \mathrm{~h}$ into the forecast.

The shear distributions in the two members were similar initially, with the dominant feature related to the circulation of the TC itself. At $24 \mathrm{~h}$, the TC circulation is also evident (this circulation is removed in the shear calculated for Figure 5), but there is also noticeably stronger environmental westerly mid-level shear west and northwest of the TC, so there is stronger environmental shear in addition to the changes due to vortex structure. As the correlations show, this large mid-level shear contributed to the slower intensification in the weak member. The structural impacts of slightly stronger shear (both mid and upper level) in the weak member, including precipitation and vortex tilt, are discussed in the next section. 

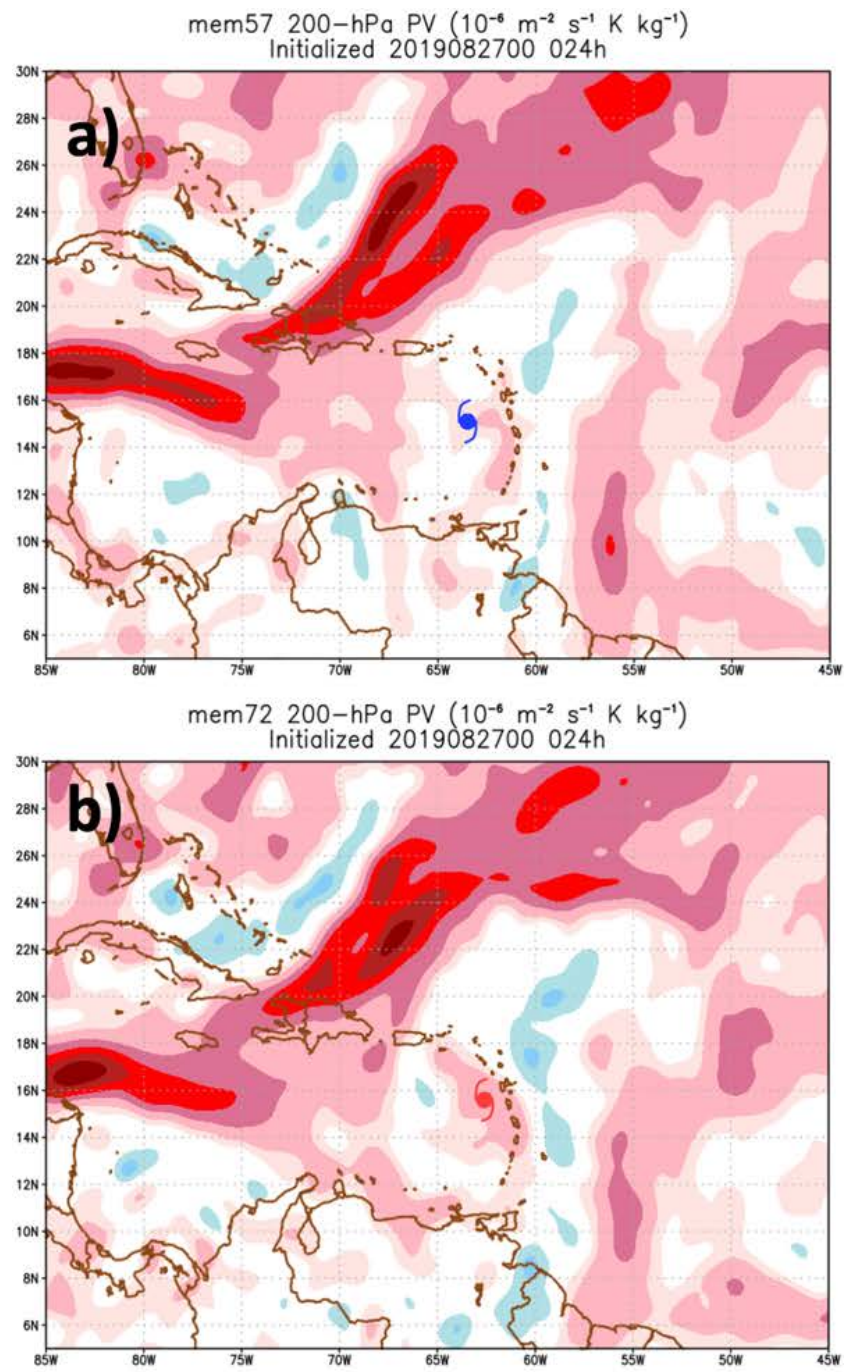

mem57 - mem72 200-hPa PV $\left(10^{-6} \mathrm{~m}^{-2} \mathrm{~s}^{-1} \mathrm{~K} \mathrm{~kg}^{-1}\right)$ Initialized $2019082700024 \mathrm{~h}$

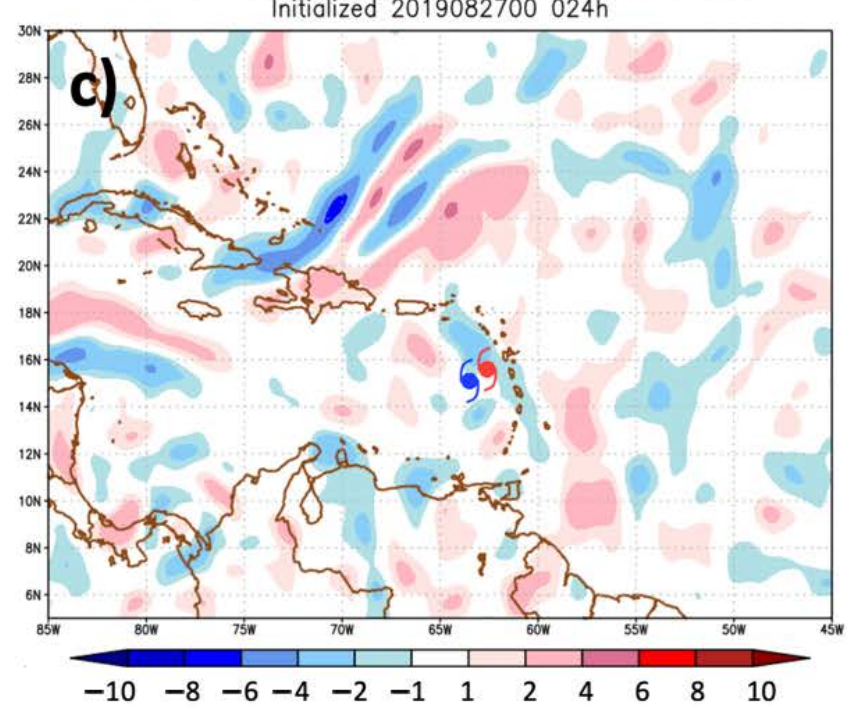

Figure 12. (a) 200-hPa potential vorticity (PV) (PVU, $1 \mathrm{PVU}=10^{-6} \mathrm{~m}^{-2} \mathrm{~s}^{-1} \mathrm{~K} \mathrm{~kg}^{-1}$ ) for the weak member at $24 \mathrm{~h}$. The model TC location is shown in blue. (b) As in (a), but for the strong member (shown in red). (c) PV difference at $24 \mathrm{~h}$ between the weak member and the strong member, with the TC locations shown in blue (the weak member) and red (the strong member). 

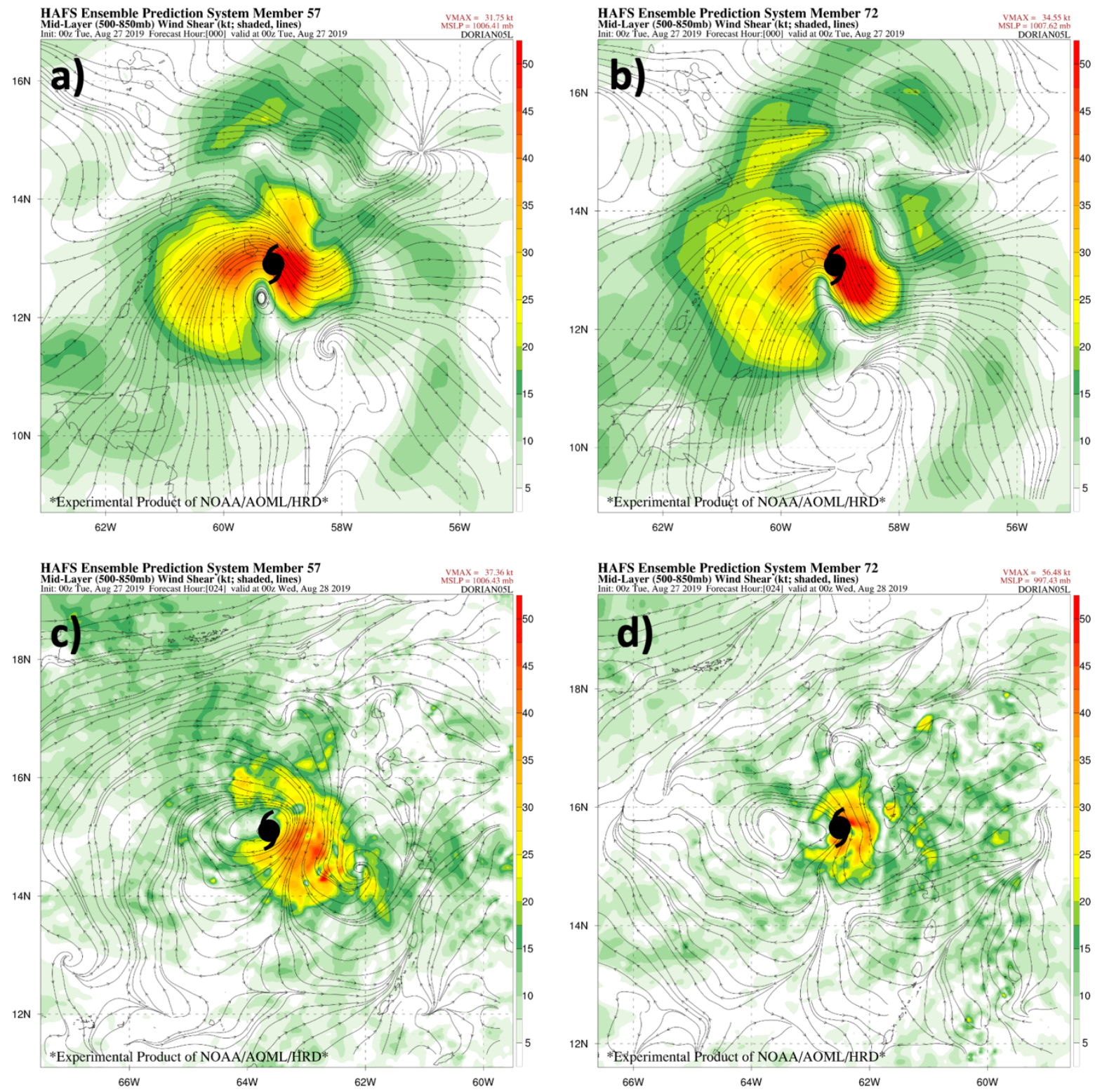

Figure 13. (a) $850-500 \mathrm{hPa}$ shear ( $\mathrm{kt}, 1 \mathrm{kt}=0.51 \mathrm{~m} \mathrm{~s}^{-1}$, shaded and streamlines) and wind (kt, wind barbs, $1 \mathrm{kt}=0.51 \mathrm{~m} \mathrm{~s}{ }^{-1}$ ) at $0 \mathrm{~h}$ for the weak member. The black hurricane symbol shows the forecast position of Dorian. (b) As in (a), but for the strong member. (c) As in (a), but for $24 \mathrm{~h}$. (d) As in (b), but for $24 \mathrm{~h}$.

\subsubsection{Structure Comparison between Two Members and with Observations}

Due to its proximity to land for much of its lifecycle, as well as the length of time that it spent in the Western Atlantic, Dorian was one of the most directly-observed tropical cyclones in modern history, including 15 missions [38] from the NOAA WP-3D Orion Hurricane Hunter aircraft, which collected Doppler radar data from the tail radar of the plane. This radar data was used for comparison between the model results and the observed TC, to understand how realistic the structural changes observed in each member were, and how these structure changes may have been related to the intensity differences in the modeled TCs. Figure 14 shows the comparison between the modeled and observed precipitation and wind structure around hour 24 of the simulations, while Figure 15 shows the comparison $24 \mathrm{~h}$ later (a new flight, near forecast hour 48). 

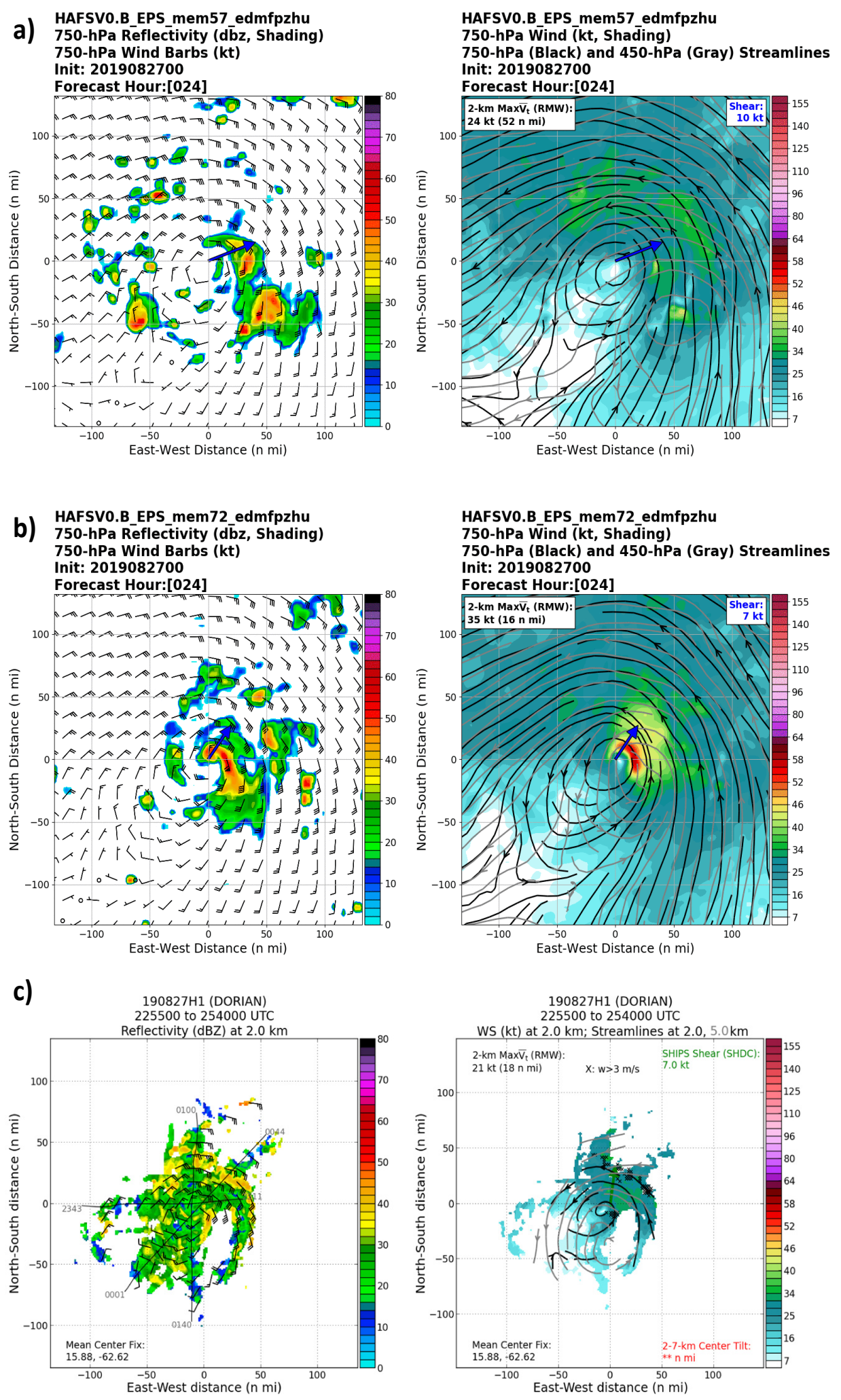

Figure 14. (a) Left: weak member (initialized 00 UTC 27 August 2019) 750-hPa reflectivity and wind barbs $\left(\mathrm{kt}, 1 \mathrm{kt}=0.51 \mathrm{~m} \mathrm{~s}^{-1}\right)$ at $24 \mathrm{~h}$. Right: weak member 750-hPa wind (shaded, kt, $1 \mathrm{kt}=0.51 \mathrm{~m} \mathrm{~s}^{-1}$ ), 750-hPa streamlines (black), 450-hPa streamlines (gray), and shear vector (blue) at $24 \mathrm{~h}$. (b) As in (a), but for the strong member. (c) Left: NOAA WP-3D radar observations of 2-km reflectivity (dBZ) and wind barbs. Right: NOAA P-3 radar observations of 2-km wind (shaded, kt, $1 \mathrm{kt}=0.51 \mathrm{~m} \mathrm{~s}^{-1}$ ), 2-km streamlines (black), 5-km streamlines (gray), and shear vector (green) for the flight period from 2225 UTC 27 August 2019 to 0140 UTC 28 August 2019. 

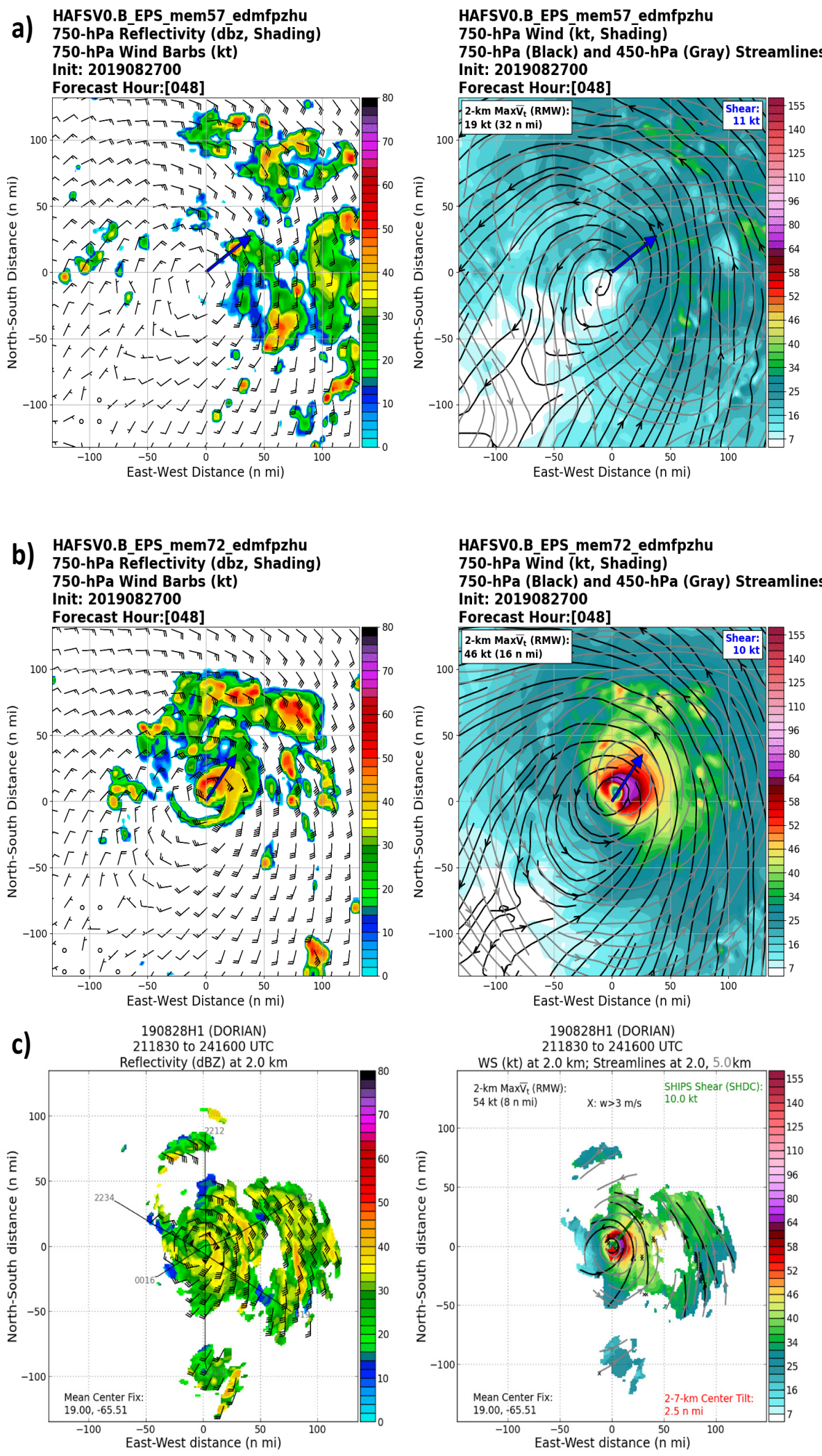

Figure 15. As in Figure 14, but for the forecasts at $48 \mathrm{~h}(\mathbf{a}, \mathbf{b})$ and the observations (c) from the flight period from 2118 UTC 28 August 2019 to 0016 UTC 29 August 2019.

At $24 \mathrm{~h}$, differences between the two members were already apparent. The mid-level vortex was tilted in both members and in observations. However, it was tilted about $40 \mathrm{~km}$ to the southeast in the strong member and observations, while in the weak member it 
was tilted about $70 \mathrm{~km}$ to the southeast. In addition, while an asymmetric precipitation structure was present in both members and observations, more precipitation wrapped around the upshear side in the strong member. Neither member had as much precipitation on the west side of the TC as was observed, but the strong member was closer to reality. From these analyses, it appears that some of the structural changes in Dorian (vortex tilt and precipitation symmetry) related to intensity change were similar to those seen in sheared TCs $[10,14,39]$, although the large-scale shear was moderate at this point (7 kt in the strong member and observations, $10 \mathrm{kt}$ in the weak member).

At $48 \mathrm{~h}$ (Figure 15), the differences between the two members are even more apparent. At this point, while the TC was near the end of this "early intensification" period, the largescale shear was almost identical in the two members and observations (10-11 kt from the southwest), but the weak member was still extremely asymmetric, with almost all of the precipitation on the east side of the low-level center. In contrast, while the large-scale precipitation pattern in the strong member was somewhat asymmetric (and in the aircraft radar data as well), there was a small, symmetric core at the center. This small but robust circulation was seen in both the reflectivity and velocity fields. In addition, while the vortex tilt was still at around $70 \mathrm{~km}$ in the weak member, it was largely reduced and the TC vortex had become nearly vertically aligned in the strong member. The radar data also showed that the observed TC had become vertically aligned by this time. Clearly, despite similar initial intensities and positions, the evolution of TC structure diverged significantly between these two members, and it should prove insightful to further examine synopticscale and storm-scale details of the evolution of these two members, to understand how Dorian was able to intensify in the Eastern Caribbean.

\subsubsection{Storm-Scale Structure Differences between Two Members}

This section examines some of the key storm-scale differences between the two divergent members, to identify some of the smaller-scale details that were important for Dorian's evolution in the Eastern Caribbean. One key difference was seen in the precipitation structure of the two members. Figure 16 shows the reflectivity at $\mathrm{z}=2 \mathrm{~km}$, as well as the precipitation types, for the weak member and the strong member at $24 \mathrm{~h}, 33 \mathrm{~h}$, and $48 \mathrm{~h}$. Observed reflectivity and precipitation types from the NOAA P-3 at times corresponding to $24 \mathrm{~h}$ and $48 \mathrm{~h}$ are also shown. For the weak member, the precipitation is initially extremely disorganized, showing a sheared pattern with almost all moderate and deep convection displaced to the south and east of the low-level center. At $33 \mathrm{~h}$, a strong band of precipitation forms and begins to wrap around the center, but this symmetrization does not last, and by $48 \mathrm{~h}$ the pattern is back to that of a highly asymmetric and disorganized system. In contrast, the symmetrization process progresses much more effectively in the strong member. At $24 \mathrm{~h}$, a comma-shaped curl of deep and moderate convection forms on the northeast (downshear) side and is beginning to wrap around the center of the TC. By $33 \mathrm{~h}$, this precipitation has effectively symmetrized into a developed inner core vortex, with much more symmetric stratiform precipitation, that is maintained for the next $6 \mathrm{~h}$ and beyond. Interestingly, a symmetric rainband can also be seen propagating away from the TC between $33 \mathrm{~h}$ and $39 \mathrm{~h}$ (not shown) in the strong member, likely a result of the diurnal cycle described by Dunion et al. [40]. In the observed radar data, the structure of the TC consists of 1-2 curved convective bands wrapping around the TC at $24 \mathrm{~h}$, that then grow into a small but robust and symmetric inner core by $48 \mathrm{~h}$, with moderate to deep convection surrounding a small eye. A prominent rain band is evident in the observations as well. It is clear from this comparison that the development of the TC core in the strong member was much more in line with observations. 

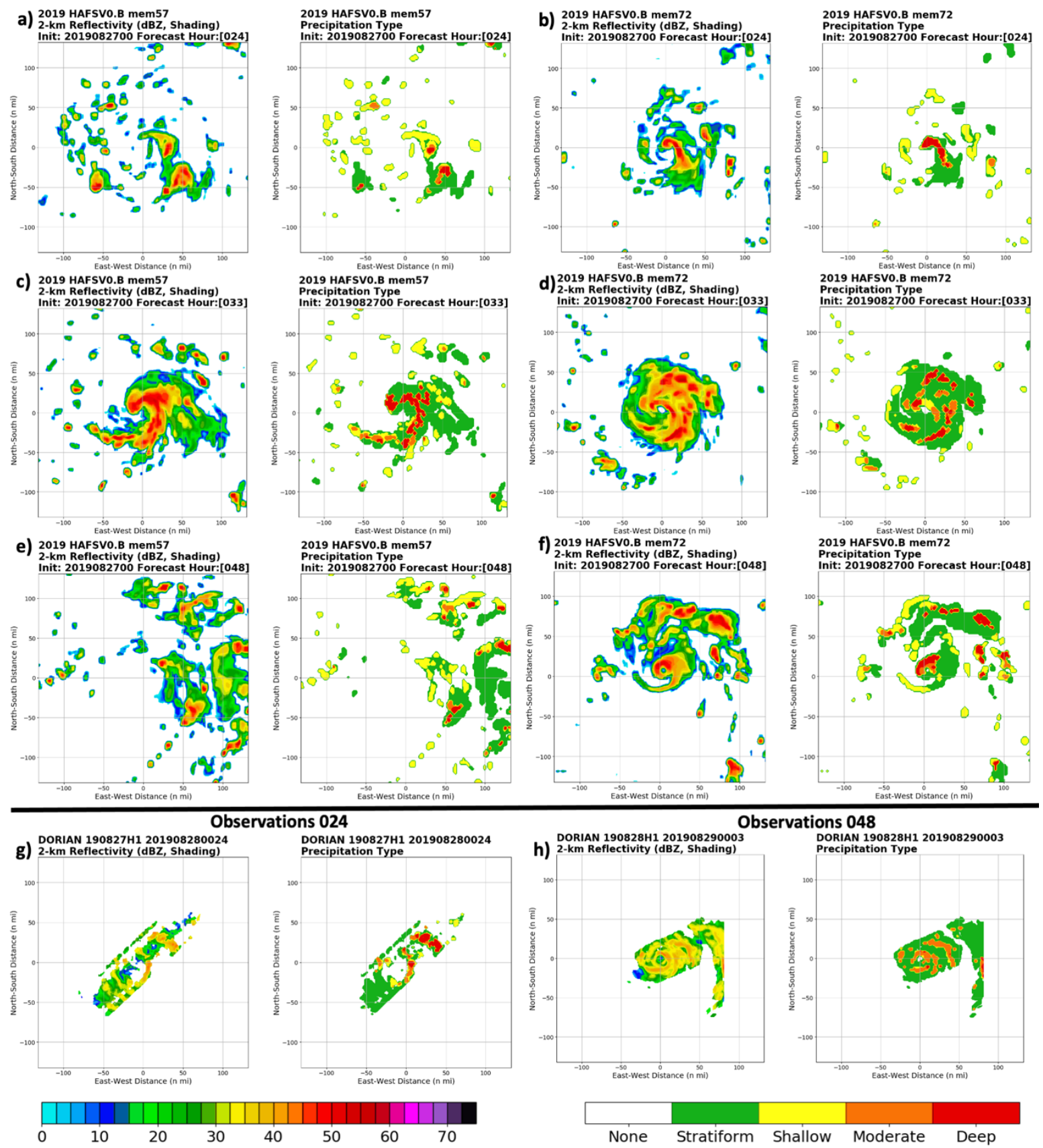

Figure 16. (a) Left-HAFS simulated reflectivity (dBZ) at $\mathrm{z}=2 \mathrm{~km}$ for the weak member at $24 \mathrm{~h}$. Right-HAFS precipitation type derived from simulated reflectivity for the weak member at $24 \mathrm{~h}$. (b) As in (a), but for the strong member. (c) As in (a), but for 33 h. (d) As in (b), but for 33 h. (e) As in (a), but for 48 h. (f) As in (b), but for 48 h. (g) Observed NOAA P-3 radar reflectivity and precipitation type from a swath across Dorian at 0024 UTC 28 August. (h) As in (g), but for 0003 UTC 29 August.

Figure 17 shows the evolution of the closure metric for the weak and strong members, and also shows the observed values of eyewall closure based on P-3 radar data. In the strong member, the stratiform precipitation has high closure initially and remains high. The closure of shallow and moderate precipitation increases through the first $48 \mathrm{~h}$. In the weak member, there is less stratiform precipitation initially, and the overall trend in closure is downward. The overall shallow, moderate, and deep convective trends in the weak member were all flat as well, despite the "spike" at $33 \mathrm{~h}$ that did not persist. Looking at the observed radar data, there were some fluctuations (likely tied to both convective pulses and data quality), but the overall trend was for an increase in closure of all precipitation types between the flight around $24 \mathrm{~h}$ and the flight around $48 \mathrm{~h}$. The evolution of these metrics in 
the strong member was more consistent observations. Clearly, the symmetrization process was much more efficient in the strong member than in the weak member, helping the storm to form a compact but robust inner core that allowed it to intensify despite the relatively dry environment around the TC. As can be seen in the evolution between Figures 13 and 14, the mid and upper level vortices in the strong member became aligned more quickly than in the weak member, which was consistent with the observed evolution of the TC. This evolution of the two members, with the stronger member having stronger downshear convection near the TC center, earlier vortex alignment, and then greater symmetrization of precipitation (and increase in closure of stratiform precipitation prior to intensification), is consistent with the evolution of Hurricane Edouard 2014 as shown in both an observational study by Rogers et al. [41] and an ensemble study by Alvey et al. [35], and also with the intensification of Hurricane Earl (2010) in simulations [42].
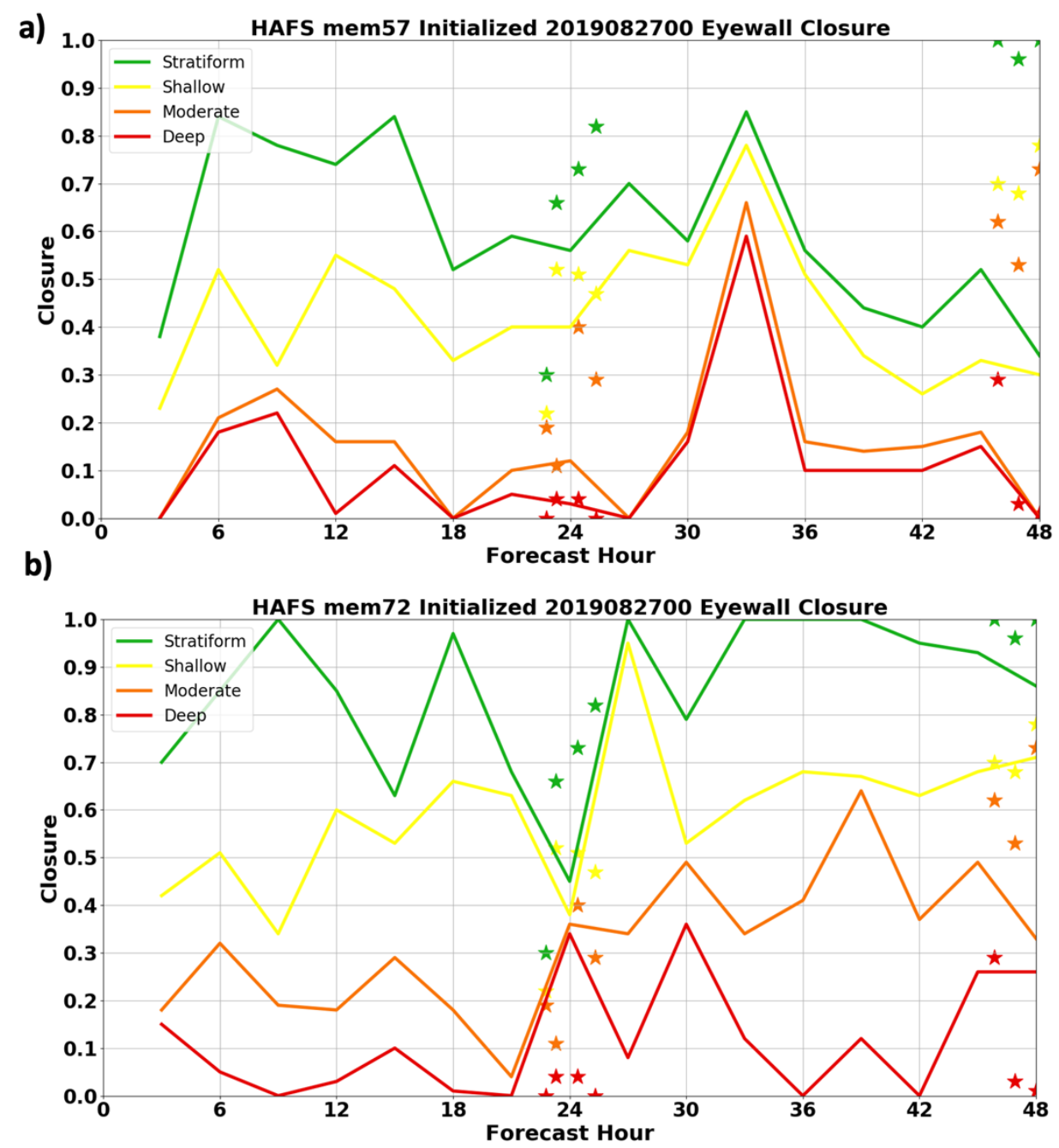

Figure 17. (a) Eyewall closure based on stratiform precipitation (green), shallow convection (yellow), moderate convection (orange), and deep convection (red) for the weak member from 3 to $48 \mathrm{~h}$. The stars show the observed values from the NOAA P-3 radar data. (b) As in (a) but for the strong member.

\section{Discussion}

This study highlights the utility of an ensemble technique using HAFS to study the evolution and intensification of a complex tropical cyclone. This builds off of prior studies using ensembles to study tropical cycle evolution, using FV3-based models [13] or other models such as WRF or HWRF $[4,7,8]$ Ensembles allow for the study of both statistics in a large group of members as well as detailed examination of case studies within the ensemble group, and this is the method applied in this study. 
The analysis presented here highlights several of the key factors leading to the early intensification of Hurricane Dorian in the Eastern Caribbean. Tropical cyclones are unique systems that span a variety of scales, and the evolution of Dorian appeared to be connected to processes on several different scales, including synoptic-scale, vortex-scale, and convective-scale. The synoptic environment, especially over and to the northeast of the TC, was significantly different between strong and weak members from the time of the analysis, and this difference grew over time. The stronger members had a large-scale environment characterized by stronger upper-level divergence and larger values of upper level moisture, which likely promoted convective growth especially on the northeast side of the developing circulation. Over time, this large-scale flow evolved into a larger upper-level anticyclone more favorably placed over the TC in the stronger members, insulating it from the shear due to a PV streamer to the west. This feature was present in both the strong and weak members, but subtle location and strength differences of the anticyclone appeared to be key to the intensity evolution of the TC. It is worth noting that some of the differences in composite synoptic flow near the mean TC position could be partially due to the differences in TC intensity, as the more favorable synoptic conditions in the stronger members positively feedback on a stronger TC circulation. For example, the greater upper-level divergence in the stronger member(s) promoted a stronger secondary circulation, which leads to increased convection [43] and latent heat release, which then, in turn, further strengthens the upper-level anticyclone and associated upper divergence. The exact timing of the related changes in synoptic flow and storm-scale convective structure can be difficult to determine, but as the precipitation analyses showed, the favorable synoptic pattern in the strong member did appear to be connected to a more organized core convective structure favorable for intensification.

The favorable synoptic environment appeared to precondition the atmosphere to allow a more symmetric convective structure to develop in the stronger ensemble members. The development of an symmetric core is key to tropical cyclone rapid intensification [44], and this was reflected in this ensemble set (and also consistent with the observed data). The visual, qualitative comparisons with aircraft data provided evidence of the importance of the core formation in the intensification of Dorian. Calculation of structure metrics allowed for a more quantitative analysis of this aspect of the forecast. Both precipitation symmetry and metrics related to vortex intensity are unsurprisingly closely related to the intensity when the TC is in the northeast Caribbean, but the correlations at earlier lead time highlight the importance of TC core formation early in this period to the overall intensity evolution. This was highlighted in the comparison of two diverging members, with a small, increasingly symmetric inner core forming in the more realistic member, while only pulsing convection with lack of consistent organization was occurring in the weaker member.

\section{Conclusions and Future Work}

In this study, we demonstrated the usefulness of a HAFS ensemble system to analyze a complex system like Hurricane Dorian. Detailed examination of the ensemble members in both composite and individual frameworks highlighted several of the key synopticscale features that evolved and allowed Dorian to intensify in the Eastern Caribbean. These factors included enhanced upper-level divergence and moisture northeast of the TC as it moved into the Caribbean, as well as the TC's more northeast location keeping it farther away from an upper-level low and its associated shear. The more favorable upper-level pattern also allowed a more robust and symmetric inner core to develop and enhance the intensification of the TC in the Eastern Caribbean. This enhanced core structure and convection (seen in the precipitation plots) may have also contributed to reducing the shear around the TC [45]. Inner-core structure metrics related to the convective and vortex structure (including tilt and eyewall closure) also showed strong correlation to the intensity at $42 \mathrm{~h}$ (as the storm reached the edge of the Caribbean). The strong member that was analyzed in detail became vertically aligned with symmetric precipitation, while the weaker member remained vertically tilted and highly asymmetric. This analysis highlights 
the importance of processes across multiple scales for TC intensification, and the complex interplay between these processes.

Future work will explore how the early intensification was related to the track differences at later periods in the ensemble set, and whether the track differences were mostly due to synoptic-scale or storm-scale processes.

Author Contributions: Conceptualization, A.H. and G.J.A.J.; methodology, A.H., G.J.A.J., L.C., and M.F.; software, A.H. and L.C.; validation, A.H., G.J.A.J., and L.C.; formal analysis; A.H.; investigation, A.H.; resources, S.G.; data curation; A.H.; writing—original draft preparation, A.H.; writing-review and editing, A.H., G.J.A.J., L.C., and M.F.; visualization, A.H.; supervision, S.G.; project administration, S.G.; funding acquisition; A.H. All authors have read and agreed to the published version of the manuscript.

Funding: This research was funded by NOAA grant NA19OAR0220187.

Institutional Review Board Statement: Not applicable.

Informed Consent Statement: Not applicable.

Data Availability Statement: Data are available upon request on the NOAA RDHPCS system.

Acknowledgments: The authors thank the NOAA RDHPCS staff for maintaining the Hera supercomputer used to perform these analyses. P. Zhu was helpful in implementing some modifications to the PBL scheme used in the simulations. The authors thank T. Alvey, J. Zhang, and three anonymous reviewers for providing helpful comments which led to improvements in the manuscript.

Conflicts of Interest: The authors declare no conflict of interest. The funders had no role in the design of the study; in the collection, analyses, or interpretation of data; in the writing of the manuscript, or in the decision to publish the results.

\section{References}

1. Velden, C.S.; Leslie, L.M. The Basic Relationship between Tropical Cyclone Intensity and the Depth of the Environmental Steering Layer in the Australian Region. Weather Forecast. 1991, 6, 244-253. [CrossRef]

2. Avila, L.; Stewart, S.; Berg, R.; Hagen, A. Hurricane Dorian Tropical Cyclone Report. Available online: https:/ /www.nhc.noaa. gov/data/tcr/AL052019_Dorian.pdf (accessed on 27 April 2020).

3. Davis, C.; Bosart, L.F. Numerical Simulations of the Genesis of Hurricane Diana (1984). Part II: Sensitivity of Track and Intensity Prediction. Mon. Weather Rev. 2002, 130, 1100-1124. [CrossRef]

4. Bassill, N.P. Accuracy of Early GFS and ECMWF Sandy (2012) Track Forecasts: Evidence for a Dependence on Cumulus Parameterization. Geophys. Res. Lett. 2014, 41, 3274-3281. [CrossRef]

5. Torn, R.D.; Snyder, C. Uncertainty of Tropical Cyclone Best-Track Information. Weather Forecast. 2012, 27, 715-729. [CrossRef]

6. Alaka, G.J.; Zhang, X.; Gopalakrishnan, S.G.; Zhang, Z.; Marks, F.D.; Atlas, R. Track Uncertainty in High-Resolution HWRF Ensemble Forecasts of Hurricane Joaquin. Weather Forecast. 2019, 34, 1889-1908. [CrossRef]

7. Nystrom, R.G.; Zhang, F.; Munsell, E.B.; Braun, S.A.; Sippel, J.A.; Weng, Y.; Emanuel, K. Predictability and Dynamics of Hurricane Joaquin (2015) Explored through Convection-Permitting Ensemble Sensitivity Experiments. J. Atmos. Sci. 2017, 75, 401-424. [CrossRef]

8. Zhang, Z.; Krishnamurti, T.N. Ensemble Forecasting of Hurricane Tracks. Bull. Am. Meteorol. Soc. 1997, 78, 2785-2796. [CrossRef]

9. Leighton, H.; Gopalakrishnan, S.; Zhang, J.A.; Rogers, R.F.; Zhang, Z.; Tallapragada, V. Azimuthal Distribution of Deep Convection, Environmental Factors, and Tropical Cyclone Rapid Intensification: A Perspective from HWRF Ensemble Forecasts of Hurricane Edouard (2014). J. Atmos. Sci. 2017, 75, 275-295. [CrossRef]

10. Rios-Berrios, R.; Torn, R.D.; Davis, C.A. An Ensemble Approach to Investigate Tropical Cyclone Intensification in Sheared Environments. Part I: Katia (2011). J. Atmos. Sci. 2015, 73, 71-93. [CrossRef]

11. Hazelton, A.T.; Bender, M.; Morin, M.; Harris, L.; Lin, S.-J. 2017 Atlantic Hurricane Forecasts from a High-Resolution Version of the GFDL FvGFS Model: Evaluation of Track, Intensity, and Structure. Weather Forecast. 2018, 33, 1317-1337. [CrossRef]

12. Hazelton, A.T.; Harris, L.; Lin, S.-J. Evaluation of Tropical Cyclone Structure Forecasts in a High-Resolution Version of the Multiscale GFDL FvGFS Model. Weather Forecast. 2018, 33, 419-442. [CrossRef]

13. Unified Forecast System—Environmental Modeling Center-Virtual Lab. Available online: https://vlab.ncep.noaa.gov/web/ environmental-modeling-center/unified-forecast-system (accessed on 5 October 2020).

14. Hazelton, A.T.; Zhang, X.; Gopalakrishnan, S.; Ramstrom, W.; Marks, F.; Zhang, J.A. High-Resolution Ensemble HFV3 Forecasts of Hurricane Michael (2018): Rapid Intensification in Shear. Mon. Weather Rev. 2020. [CrossRef]

15. Harris, L.M.; Lin, S.J. A Two-Way Nested Global-Regional Dynamical Core on the Cubed-Sphere Grid. Mon. Weather Rev. 2012, 141, 283-306. [CrossRef] 
16. Han, J.; Wang, W.; Kwon, Y.C.; Hong, S.-Y.; Tallapragada, V.; Yang, F. Updates in the NCEP GFS Cumulus Convection Schemes with Scale and Aerosol Awareness. Weather Forecast. 2017, 32, 2005-2017. [CrossRef]

17. Han, J.; Witek, M.L.; Teixeira, J.; Sun, R.; Pan, H.-L.; Fletcher, J.K.; Bretherton, C.S. Implementation in the NCEP GFS of a Hybrid Eddy-Diffusivity Mass-Flux (EDMF) Boundary Layer Parameterization with Dissipative Heating and Modified Stable Boundary Layer Mixing. Weather Forecast. 2016, 31, 341-352. [CrossRef]

18. Wang, W.; Sippel, J.A.; Abarca, S.; Zhu, L.; Liu, B.; Zhang, Z.; Mehra, A.; Tallapragada, V. Improving NCEP HWRF Simulations of Surface Wind and Inflow Angle in the Eyewall Area. Weather Forecast. 2018, 33, 887-898. [CrossRef]

19. Zhu, P.; Tyner, B.P.; Zhang, J.; Abarca, S.; Aligo, E.; Marks, F.D.; Zhang, Z.; Tallapragada, V. Role of In-Cloud Turbulent Mixing in the Eyewall and Rainbands in Tropical Cyclone Intensification. In Proceedings of the 33rd Conference on Hurricanes and Tropical Meteorology, Ponte Vedra Beach, FL, USA, 16 April 2018.

20. Iacono, M.J.; Delamere, J.S.; Mlawer, E.J.; Shephard, M.W.; Clough, S.A.; Collins, W.D. Radiative Forcing by Long-Lived Greenhouse Gases: Calculations with the AER Radiative Transfer Models. J. Geophys. Res. Atmos. 2008, 113. [CrossRef]

21. Chen, J.-H.; Lin, S.-J. Seasonal Predictions of Tropical Cyclones Using a 25-Km-Resolution General Circulation Model. J. Clim. 2012, 26, 380-398. [CrossRef]

22. Bender, M.A.; Ginis, I.; Tuleya, R.; Thomas, B.; Marchok, T. The Operational GFDL Coupled Hurricane-Ocean Prediction System and a Summary of Its Performance. Mon. Weather Rev. 2007, 135, 3965-3989. [CrossRef]

23. Zhou, X.; Zhu, Y.; Hou, D.; Luo, Y.; Peng, J.; Wobus, R. Performance of the New NCEP Global Ensemble Forecast System in a Parallel Experiment. Weather Forecast. 2017, 32, 1989-2004. [CrossRef]

24. DeMaria, M.; Kaplan, J. A Statistical Hurricane Intensity Prediction Scheme (SHIPS) for the Atlantic Basin. Weather Forecast. 1994, 9, 209-220. [CrossRef]

25. Didlake, A.C.; Houze, R.A. Convective-Scale Downdrafts in the Principal Rainband of Hurricane Katrina (2005). Mon. Weather Rev. 2009, 137, 3269-3293. [CrossRef]

26. Rogers, R.F.; Reasor, P.D.; Zawislak, J.A.; Nguyen, L.T. Precipitation Processes and Vortex Alignment during the Intensification of a Weak Tropical Cyclone in Moderate Vertical Shear. Mon. Weather Rev. 2020, 148, 1899-1929. [CrossRef]

27. Steiner, M.; Houze, R.A.; Yuter, S.E. Climatological Characterization of Three-Dimensional Storm Structure from Operational Radar and Rain Gauge Data. J. Appl. Meteorol. 1995, 34, 1978-2007. [CrossRef]

28. Rogers, R. Convective-Scale Structure and Evolution during a High-Resolution Simulation of Tropical Cyclone Rapid Intensification. J. Atmos. Sci. 2010, 67, 44-70. [CrossRef]

29. Matyas, C.J.; Zick, S.E.; Tang, J. Using an Object-Based Approach to Quantify the Spatial Structure of Reflectivity Regions in Hurricane Isabel (2003). Part I: Comparisons between Radar Observations and Model Simulations. Mon. Weather Rev. 2018, 146, 1319-1340. [CrossRef]

30. Rogers, R.; Reasor, P.; Lorsolo, S. Airborne Doppler Observations of the Inner-Core Structural Differences between Intensifying and Steady-State Tropical Cyclones. Mon. Weather Rev. 2013, 141, 2970-2991. [CrossRef]

31. Hazelton, A.T.; Hart, R.E.; Rogers, R.F. Analyzing Simulated Convective Bursts in Two Atlantic Hurricanes. Part II: Intensity Change Due to Bursts. Mon. Weather Rev. 2017, 145, 3095-3117. [CrossRef]

32. Chen, X.; Xue, M.; Fang, J. Rapid Intensification of Typhoon Mujigae (2015) under Different Sea Surface Temperatures: Structural Changes Leading to Rapid Intensification. J. Atmos. Sci. 2018, 75, 4313-4335. [CrossRef]

33. Hazelton, A.T.; Hart, R.E. Hurricane Eyewall Slope as Determined from Airborne Radar Reflectivity Data: Composites and Case Studies. Weather Forecast. 2012, 28, 368-386. [CrossRef]

34. Zhang, J.A.; Nolan, D.S.; Rogers, R.F.; Tallapragada, V. Evaluating the Impact of Improvements in the Boundary Layer Parameterization on Hurricane Intensity and Structure Forecasts in HWRF. Mon. Weather Rev. 2015, 143, 3136-3155. [CrossRef]

35. Alvey, G.R.; Zipser, E.; Zawislak, J. How Does Hurricane Edouard (2014) Evolve toward Symmetry before Rapid Intensification? A High-Resolution Ensemble Study. J. Atmos. Sci. 2020, 77, 1329-1351. [CrossRef]

36. Zawislak, J.; Jiang, H.; Alvey, G.R.; Zipser, E.J.; Rogers, R.F.; Zhang, J.A.; Stevenson, S.N. Observations of the Structure and Evolution of Hurricane Edouard (2014) during Intensity Change. Part I: Relationship between the Thermodynamic Structure and Precipitation. Mon. Weather Rev. 2016, 144, 3333-3354. [CrossRef]

37. Finocchio, P.M.; Majumdar, S.J.; Nolan, D.S.; Iskandarani, M. Idealized Tropical Cyclone Responses to the Height and Depth of Environmental Vertical Wind Shear. Mon. Weather Rev. 2016, 144, 2155-2175. [CrossRef]

38. Dorian. 2019. Available online: https://www.aoml.noaa.gov/hrd/Storm_pages/dorian2019/mission.html (accessed on 5 October 2020).

39. Chen, H.; Gopalakrishnan, S.G. A Study on the Asymmetric Rapid Intensification of Hurricane Earl (2010) Using the HWRF System. J. Atmos. Sci. 2015, 72, 531-550. [CrossRef]

40. Dunion, J.P.; Thorncroft, C.D.; Velden, C.S. The Tropical Cyclone Diurnal Cycle of Mature Hurricanes. Mon. Weather Rev. 2014, 142, 3900-3919. [CrossRef]

41. Rogers, R.F.; Zhang, J.A.; Zawislak, J.; Jiang, H.; Alvey, G.R.; Zipser, E.J.; Stevenson, S.N. Observations of the Structure and Evolution of Hurricane Edouard (2014) during Intensity Change. Part II: Kinematic Structure and the Distribution of Deep Convection. Mon. Weather Rev. 2016, 144, 3355-3376. [CrossRef]

42. Zhang, J.A.; Rogers, R.F. Effects of Parameterized Boundary Layer Structure on Hurricane Rapid Intensification in Shear. Mon. Weather Rev. 2019, 147, 853-871. [CrossRef] 
43. Holland, G.J.; Merrill, R.T. On the Dynamics of Tropical Cyclone Structural Changes. Q. J. R. Meteorol. Soc. 1984, 110, 723-745. [CrossRef]

44. Kieper, M.E.; Jiang, H. Predicting Tropical Cyclone Rapid Intensification Using the $37 \mathrm{GHz}$ Ring Pattern Identified from Passive Microwave Measurements. Geophys. Res. Lett. 2012, 39. [CrossRef]

45. Ryglicki, D.R.; Doyle, J.D.; Hodyss, D.; Cossuth, J.H.; Jin, Y.; Viner, K.C.; Schmidt, J.M. The Unexpected Rapid Intensification of Tropical Cyclones in Moderate Vertical Wind Shear. Part III: Outflow-Environment Interaction. Mon. Weather Rev. 2019, 147, 2919-2940. [CrossRef] 